\title{
NUMERICAL MODELLING AND EXPERIMENTAL VALIDATION IN SELECTIVE LASER MELTING
}

\author{
MICHELE CHIUMENTI $^{\dagger}$, ERIC NEIVA $^{\dagger}$, EMILIO SALSI $^{\dagger}$, MIGUEL CERVERA $^{\dagger}$, SANTIAGO BADIA $^{\dagger}$, \\ JOAN MOYA ${ }^{\dagger}$, ZHUOER CHEN $^{\ddagger}$, CAROLINE LEE $^{\ddagger}$, AND CHRISTOPHER DAVIES ${ }^{\ddagger}$
}

\footnotetext{
† Centre Internacional de Mètodes Numèrics en Enginyeria (CIMNE), Building C1, Campus Nord UPC, Gran Capitán S/N, E-08034 Barcelona, Spain, \& Universitat Politècnica de Catalunya, Jordi Girona 1-3, Edifici C1, E-08034 Barcelona, Spain. \{michele,eneiva,esalsi,mcervera,sbadia,jmoya\}@cimne.upc.edu.

‡ Department of Mechanical and Aerospace Engineering, Monash University, VIC 3800, Australia. Monash Centre for Additive Manufacturing, Monash University, VIC 3800, Australia.
}

\begin{abstract}
In this work a finite-element framework for the numerical simulation of the heat transfer analysis of additive manufacturing processes by powder-bed technologies, such as Selective Laser Melting, is presented. These kind of technologies allow for a layer-by-layer metal deposition process to cost-effectively create, directly from a CAD model, complex functional parts such as turbine blades, fuel injectors, heat exchangers, medical implants, among others. The numerical model proposed accounts for different heat dissipation mechanisms through the surrounding environment and is supplemented by a finite-element activation strategy, based on the born-dead elements technique, to follow the growth of the geometry driven by the metal deposition process, in such a way that the same scanning pattern sent to the numerical control system of the AM machine is used. An experimental campaign has been carried out at the Monash Centre for Additive Manufacturing using an EOSINT-M280 machine where it was possible to fabricate different benchmark geometries, as well as to record the temperature measurements at different thermocouple locations. The experiment consisted in the simultaneous printing of two walls with a total deposition volume of $107 \mathrm{~cm}^{3}$ in 992 layers and about 33,500 s build time. A large number of numerical simulations have been carried out to calibrate the thermal FE framework in terms of the thermophysical properties of both solid and powder materials and suitable boundary conditions. Furthermore, the large size of the experiment motivated the investigation of two different model reduction strategies: exclusion of the powder-bed from the computational domain and simplified scanning strategies. All these methods are analysed in terms of accuracy, computational effort and suitable applications.
\end{abstract}

Keywords: Additive Manufacturing (AM) process, Metal Deposition (MD) process, powder-bed technologies, Selective Laser Melting (SLM), Finite-element (FE) modelling, Heat transfer analysis.

\section{CONTEnTS}

1. Introduction

2. Heat transfer analysis

2.1. Governing equation

2.2. Boundary conditions.

3. FE modelling of the AM process

3.1. Space and time discretization of the heat source $\quad 7$

3.2. Definition of scanning strategy

4. Experimental campaign

5. Numerical results and discussion 11

5.1. Initial calibration of the model $r$

5.2. Numerical model assessment $\quad 15$

6. Conclusions 21

Date: September 7, 2017. 


\section{INTRODUCTION}

Additive Manufacturing (AM) or 3D Printing refers to a group of manufacturing processes that build up a three-dimensional object layer upon layer, directly from a Computer-Aided Design (CAD) model. This technology has been traditionally used for rapid prototyping using plastic materials. Nowadays, it allows for the 3D printing of metallic components ready to be exploited for many industrial applications.

The most important benefit of AM is the ability to cost-effectively create objects with shapes and properties that were previously near-impossible to produce with conventional manufacturing processes, such as casting or forging. AM can easily print very complex geometries with cavities, thin walls or lattice structures and it is also competitive for customised design in a short production time.

This work addresses the numerical simulation of AM processes of metal components by powder-bed technologies, such as Selective Laser Melting (SLM), Direct Metal Laser Sintering (DMLS) or Electron Beam Melting (EBM). Many industrial sectors are adopting them to fabricate their products, such as turbine blades, fuel injectors, and microturbines in aerospace and aeronautics; wheel suspensions, heat exchangers, and break disks in the automotive industry; dental bridges and implants in the medical industry, or even jewels in the consumer goods sector.

A typical printing process by powder-bed technology, such as DMLS in Figure 1, occurs in a closed
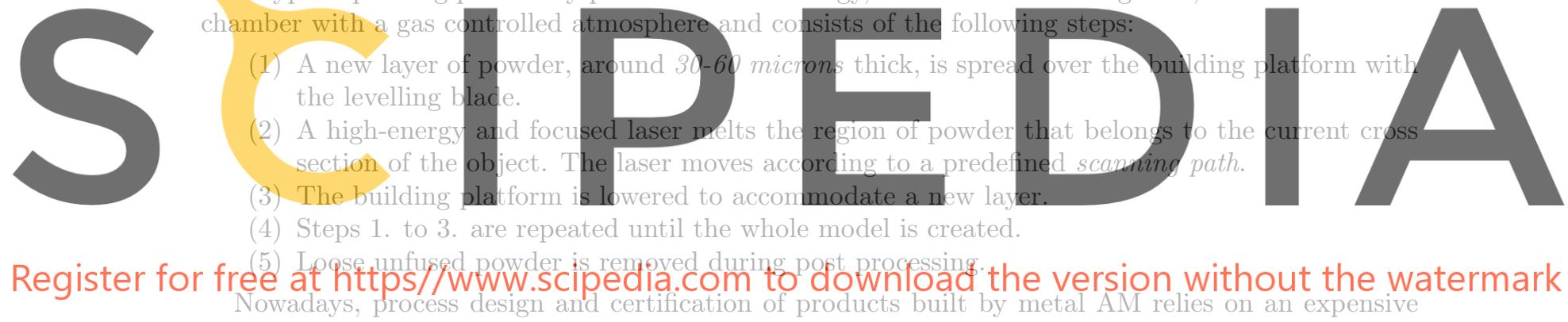

and time-consuming trial-and-error procedure. This situation prevents a wider adoption of these technologies by the industry. In order to leverage the freedom in design, cost efficiency and immediacy that AM offers, one possible solution is to shift to a virtual-based design, using predictive computer simulation tools.

Many researchers have already used the Finite-Element (FE) method to analyse metal deposition processes in AM with different technologies [1, 2, 11, 22, 28, 29, 36, 45], often taking advantage from the knowledge acquired in modelling other metal forming processes, such as casting or welding $[3,5$, $10,12,18,27]$.

FE modelling has been mainly employed to assess the influence of process parameters [30, 38, 46] and to evaluate distortions and residual stresses $[9,13,16,23,34]$. In this sense, thermal modelling, apart from being an input for the mechanical analysis, is fundamental to characterise the melt pool and the microstructure in an AM process [20, 25, 33, 41] and also guides the selection of the printing process parameters in engineering design [26, 32, 44].

The scope of this work is the FE analysis of the AM process by metal deposition at the component scale. Hence the focus is the study of the heat transfer process according to the energy introduced into the system by the heat source (laser, electron beam, etc.), as well as the heat dissipation through the boundaries of the domain which define the component during its fabrication. The phenomena occurring in the melt pool and in the surrounding Heat Affected Zone (HAZ) can also be analysed [7, $17,24,35,37,40]$, but are out of the scope of this work.

Furthermore, two aspects deserve especial attention when modelling powder-bed technologies. First, the lateral walls of the component are in permanent contact with the unsintered powder throughout 
the printing and cooling processes. As a consequence, heat conduction through the powder must be modelled. Second, the layer thickness is typically very small (about 30 to 60 microns), so that building industrial parts requires the deposition of thousands of layers. Therefore, computational efficiency is paramount.

Computational complexity is one of the reasons why most experimental studies with powder-bed technologies consider short single-part builds of less than 15 layers and $1 \mathrm{~cm}^{3}$ volume [14, 22, 30, 36]. Fewer works attempt at higher deposition volumes [15, 34], longer processes [16], or multiple parts [19, 34], but barely any of these experimental builds approach the limits of current machines.

Besides, strict discretization requirements [47], specifying mesh sizes smaller than the laser beam spot size, are necessary to obtain an accurate local thermal response, especially, to capture the peak temperature distribution, but they also increase the computational load to a point where engineering applications are out of reach.

Several methods have been introduced to overcome this burden. On the one hand, adaptive mesh refinement and coarsening have been explored to reduce the size of the spatial problem [15, 31]. On the other hand, reduced models with simplified scanning strategies have been introduced [19, 21]. These models are not capable of predicting the complex thermal history (local superheating and supercooling). Therefore, they are not suitable for further mechanical or microscale analyses. However, they are able to capture an accurate global thermal response. For this reason, they are a reliable and efficient alternative for other engineering applications, such as optimisation of the process parameters or process planning. In spite of the benefits, the authors consider that these reduction strategies have been object of few numerical analysis and contrast with physical experiments.
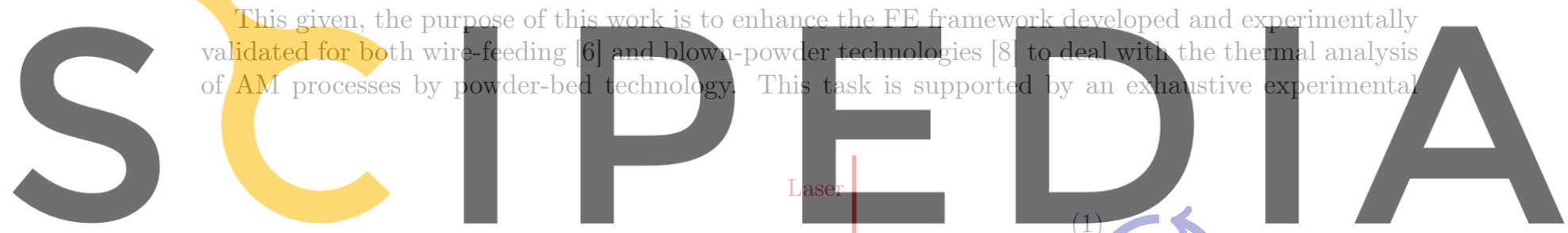

Register for free at https//www.scipedia.com to download the version without the watermark

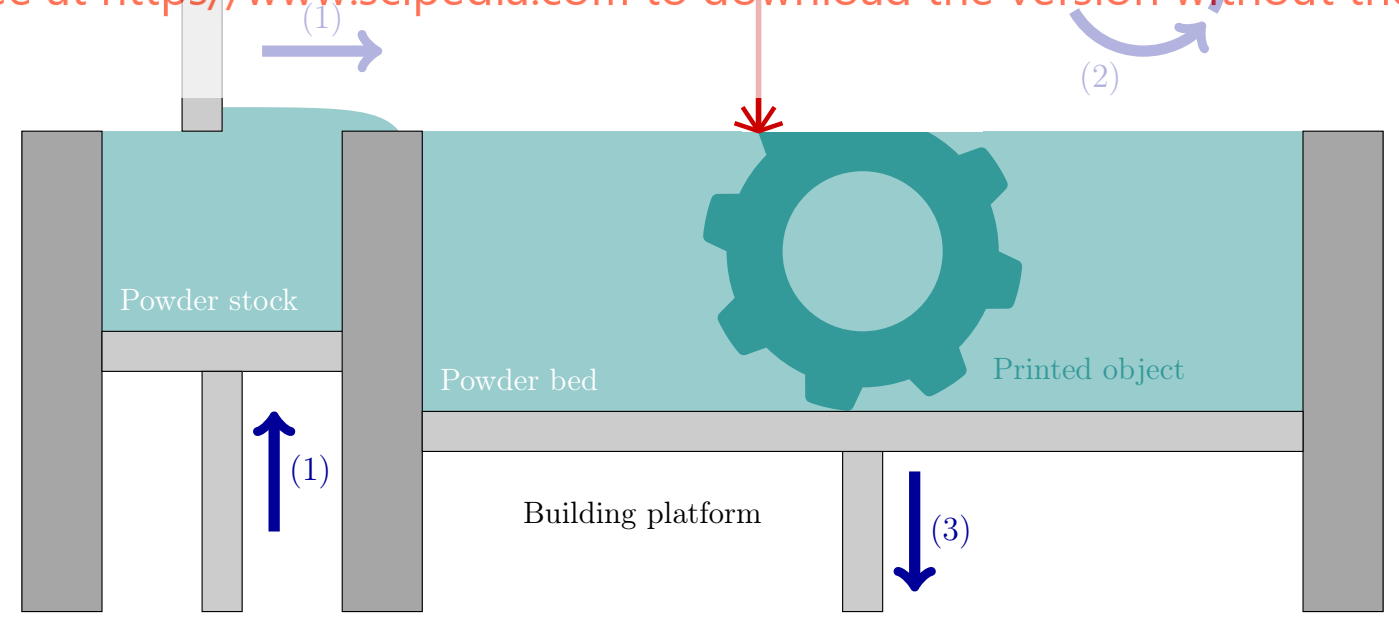

FiguRE 1. A printing process by DMLS. (1) A new layer of powder, around 30-60 microns thick, is spread over the building platform with the levelling blade. (2) A laser source melts the region of powder that belongs to the current cross section of the object. (3) The building platform is lowered to accommodate a new layer. (4) Steps 1. to 3. are repeated until the whole model is created. (5) Loose unfused powder is removed during post processing. 
campaign carried out at the Monash Centre for Additive Manufacturing (MCAM) in Melbourne, Australia, using an EOSINT M280 machine and Ti-6Al-4V powder. The scale of the experiment is unprecedented and representative of big industrial cases: simultaneous printing of two $95 \mathrm{~cm}^{3}$ and 12 $\mathrm{cm}^{3}$ walls in 992 layers and about $33,500 \mathrm{~s}$ build time.

The computational framework proposed here is calibrated by comparing the temperature evolution obtained at different thermocouple locations during the full duration of the AM process with the corresponding experimental measurements. The experimental setting is also used to investigate different numerical approaches, in order to find the best simulation practice when dealing with powder-bed technologies.

With regards to the thermal loss through the powder, two alternatives are examined: (1) including the powder-bed into the computational model with appropriate estimations of the thermophysical properties of the powder, as done in [14,34], or (2) a novel approach that excludes the powder-bed and models the corresponding heat loss with an equivalent heat flux through the lateral walls of the component as immersed into the unsintered powder.

As for the computational complexity, this work assesses the impact of considering simplified scanning strategies on the accuracy of the solution and the simulation time. The analysis ends with a comparative evaluation of the advantages and disadvantages of each model reduction approach and recommended applications.

The outline of this work is as follows. First, the formulation of the heat transfer problem is detailed in Section 2. The FE activation technique used to simulate the metal deposition is explained in Section 3. Section 4 describes the experimental setting at the MCAM. The calibration of the numerical model and the evaluation of the different simulation approaches is addressed in Section 5 . Finally, Section 6
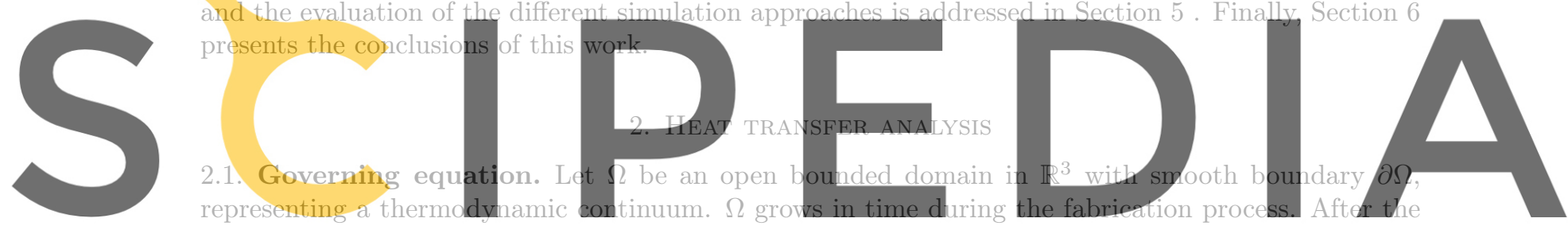

printing, it remains fixed, while cooling down to the room temperature.

$$
\dot{\mathrm{H}}=-\nabla \cdot \mathrm{q}+\dot{\mathrm{r}}, \quad \text { in } \Omega, \mathrm{t}>0,
$$

where $\dot{H}$ is the rate of enthalpy per unit volume, $\dot{\mathrm{r}}$ the heat supplied to the system per unit volume by the internal sources and $\mathbf{q}$ the heat conduction flux.

For an AM process, the heat source $\dot{\mathrm{r}}(\mathrm{t})$ is the energy input from a very intense and concentrated laser beam that moves in time according to a user-defined deposition sequence, the scanning path.

The enthalpy rate per unit volume $\dot{\mathrm{H}}$ is defined, in terms of the temperature $\mathrm{T}$ and the rate of the latent heat released/absorbed during the phase-change process $\dot{L}$, as

$$
\dot{\mathrm{H}}\left(\mathrm{T}, f_{L}\right)=C(\mathrm{~T}) \dot{\mathrm{T}}+\rho(\mathrm{T}) \dot{L},
$$

where $C(\mathrm{~T})$ is the (temperature dependent) heat capacity coefficient, given by the product of the density of the material $\rho(\mathrm{T})$ and the specific heat $c(\mathrm{~T})$.

The amount of latent heat is negligible in front of the energy input introduced by the heat source. Moreover, in the HAZ, latent heat is absorbed when the laser fuses the powder particles. Immediately after, the material solidifies and the same amount of latent heat is released. These two phase transformations occur very fast, compared to the thermal diffusion process. As a result, the energy balance due to the phase change is null and very localised at the HAZ, so its global effect is minor in the heat transfer analysis [8].

According to this, the balance of energy equation can be stated as

$$
C(\mathrm{~T}) \dot{\mathrm{T}}-\nabla \cdot(k(\mathrm{~T}) \nabla \mathrm{T})=\dot{\mathrm{r}}, \quad \text { in } \Omega, \quad \mathrm{t}>0,
$$


where the conduction heat flux per unit area $\mathbf{q}$ is proportional to the gradient of temperature, according to Fourier's law:

$$
\mathbf{q}=-k(\mathrm{~T}) \nabla \mathrm{T}
$$

with $k(\mathrm{~T})>0$ the (temperature-dependent) thermal conductivity.

2.2. Boundary conditions. Due to the high conductivity of metals, heat conduction through the building platform and thermal loss through the loose powder in which the component is immersed are the predominant heat transfer mechanisms in powder-bed technology. However, heat radiation and convection through the surfaces in contact with the environment must also be accounted for. Figure 2 illustrates the boundary conditions of the problem.

Considering a partition $\left(\partial \Omega_{c}, \partial \Omega_{p}, \partial \Omega_{e}\right)$ of the boundary $\partial \Omega$, where $\partial \Omega_{c}$ represents the contact surface with the printing platform, $\partial \Omega_{p}$ the contact surface with the powder-bed, and $\partial \Omega_{e}$ the external surface in contact with the surrounding environment, the boundary conditions are expressed as:

2.2.1. Heat conduction through the building platform. Typically, the dimensions of the building platform (e.g. its thermal inertia) are much larger than the printed part. Hence, it is possible to prescribe the temperature on the contact surface $\Omega_{c}$ as

$$
\mathrm{T}=\mathrm{T}_{c}, \quad \text { on } \partial \Omega_{c},
$$

where $T_{c}$ is the temperature of the building platform.

2.2.2. Heat conduction through the powder bed. If the powder bed is included in the computational domain, the thermophysical properties of the powder are established in terms of the properties of the

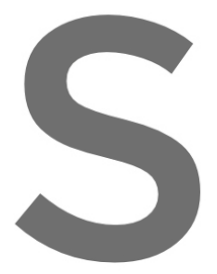
solid material and the porosity of the granylar bed,
The density and the specific heat are straightfor
\[ c_{p}=c_{\text {solid }} \text {, } \]
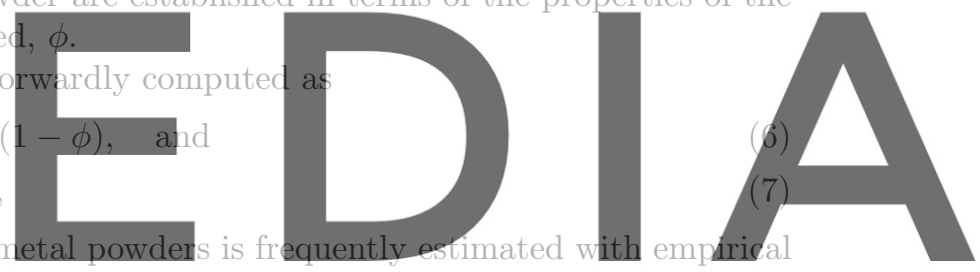

expressions, that also depend on the conductivity of the surrounding air or gas, $k_{\text {gas }}$. Among several

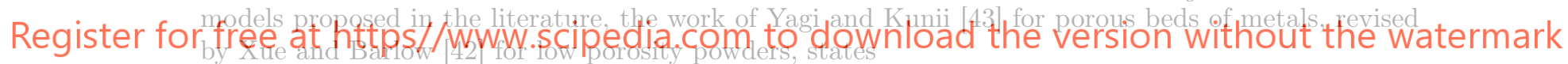

$$
k_{p}=\left(6.3+22 \sqrt{0.09 k_{\text {solid }}-0.016}\right) \frac{k_{\text {solid }}(1-\phi)}{\left(k_{\text {solid }} / k_{\text {gas }}\right)\left(10^{0.523-0.594 \phi}\right)-1}
$$

Alternatively, if the powder bed is not included in the computational domain, the heat loss by conduction through the powder $q_{p}$ can be expressed using an equivalent boundary condition, as

$$
q_{p}(\mathrm{~T})=h_{p}\left(\mathrm{~T}-\mathrm{T}_{p}\right), \quad \text { on } \partial \Omega_{p},
$$

where $\mathrm{T}_{p}$ is the temperature of the powder far enough from the HAZ, and $h_{p}(\mathrm{~T})$ denotes the HTC by conduction between the powder and the component.

$\mathrm{T}_{p}$ should be known or duly estimated in time during the full duration of the AM process, but a constant value can be used, if the thermal interference among the different components, being printed on the same platform at the same time, is negligible.

On the other hand, $h_{p}(\mathrm{~T})$ is computed as

$$
h_{p}(\mathrm{~T})=\frac{k_{p}(\mathrm{~T})}{s_{p}},
$$

where $s_{p}$ accounts for the average size of the region around the component, thermally affected by the printing process (e.g. with presence of strong thermal gradients), as shown in Figure 3

Introducing an equivalent boundary condition for heat transfer through the powder-bed simplifies the physics of the problem, but has obvious consequences in the error of the predictions. On the one hand, it leads to a reduced computational model with less thermophysical properties of the metal powder to be determined. On the other hand, though suitable for sensitivity analysis and optimisation 


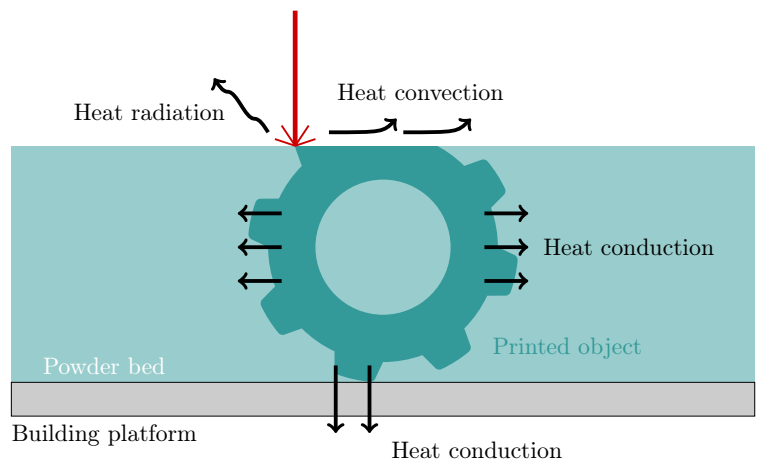

Figure 2. A close-up of Figure 1 gathering the boundary conditions of the problem: (1) Heat conduction through the building platform. (2) Heat conduction through the powder bed. (3) Heat convection and heat radiation through the free surface.
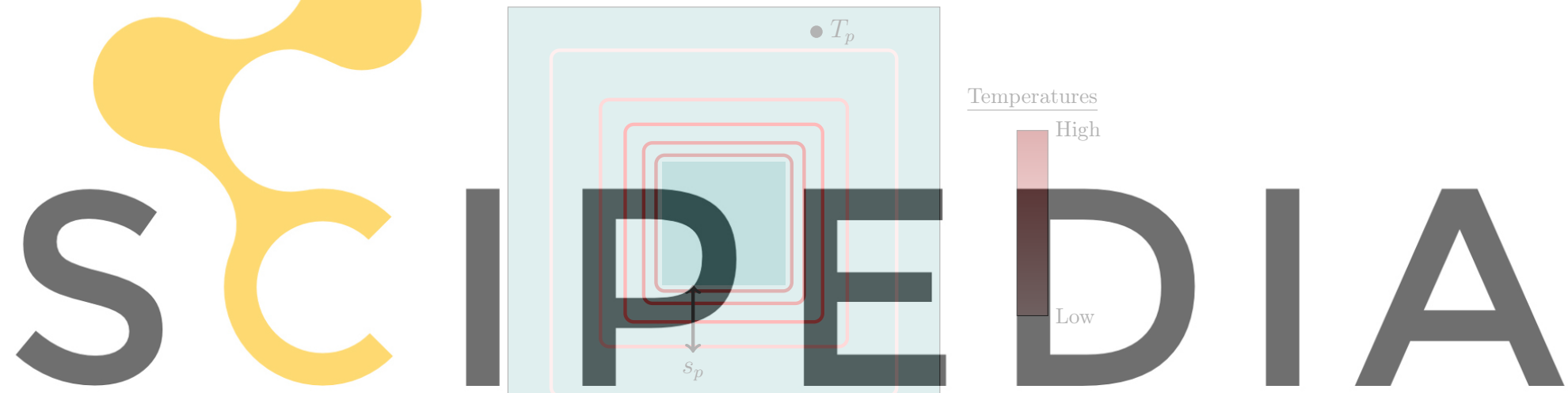

Register for free at https//www.scipedia.com to download the version without the watermark

FIGURE 3. $T_{p}$ is the average temperature of the powder far from the HAZ, where

the thermal field is not much affected by the temperature gradient originated by the

printing process, and $s_{p}$ is the average size of the process affected zone.

of the process parameters, this approach is not recommended for applications with strict accuracy requirements.

2.2.3. Heat convection through the surrounding environment. The heat loss by convection through the surrounding environment $q_{c o n v}$ can also be expressed by Newton's law as

$$
q_{\text {conv }}(\mathrm{T})=h_{\text {conv }}\left(\mathrm{T}-\mathrm{T}_{e}\right), \quad \text { on } \partial \Omega_{e},
$$

where $h_{\text {conv }}(\mathrm{T})$ denotes the HTC by convection through the surrounding environment and $\mathrm{T}_{e}$ is the temperature of the gas inside the machine chamber. $\mathrm{T}_{e}$ can be assumed constant if the gas temperature is controlled or the component is very small compared to the size of the chamber.

2.2.4. Heat radiation. Radiation is an important heat loss mechanism at the HAZ, due to the hightemperature field induced by the heat source. The radiation heat flux $q_{\text {rad }}$ can be calculated using Stefan-Boltzmann's law:

$$
q_{\text {rad }}(\mathrm{T})=\sigma \epsilon\left(\mathrm{T}^{4}-\mathrm{T}_{e}^{4}\right), \quad \text { on } \partial \Omega_{e}
$$

Here, $\sigma$ is the Stefan-Boltzmann constant and $\epsilon$ is the emissivity of the radiating surface, a measure of the efficiency of the body as a radiation emitter. The contribution of heat radiation can also be 
expressed as

where

$$
q_{\text {rad }}(\mathrm{T})=h_{\text {rad }}\left(\mathrm{T}-\mathrm{T}_{e}\right), \quad \text { on } \partial \Omega_{e},
$$

$$
h_{\text {rad }}(\mathrm{T})=\sigma \epsilon\left(\mathrm{T}^{3}+\mathrm{T}^{2} \mathrm{~T}_{e}+\mathrm{TT}_{e}^{2}+\mathrm{T}_{e}^{3}\right) .
$$

Heat is lost through the environment by a combination of convection and radiation. In practice, it is difficult to discriminate the effects of both heat transfer modes. For this reason, the numerical model assumes a combined heat transfer law, accounting for both heat convection and radiation:

$$
q_{\text {loss }}(\mathrm{T})=h_{\text {loss }}\left(\mathrm{T}-\mathrm{T}_{e}\right), \quad \text { on } \partial \Omega_{e} .
$$

In this case, $q_{\text {loss }}$ represents the heat flux due to the simultaneous convection and radiation mechanisms, and $h_{\text {loss }}$ is the corresponding equivalent HTC.

\section{FE MODELLING OF THE AM PROCESS}

Metal deposition is modelled by moving the heat source along a predefined scanning pattern. Hence, the geometry of the component grows in time according to the sintering process that transforms metal powder into a new solid layer.

The numerical simulation of this process requires an ad-hoc procedure to apply the volumetric heat source $\dot{r}$ in space and time to the elements affected by the moving energy input, as well as to include into the computational domain those elements forming a new layer of material. This procedure is referred to as the FE activation technique.

The activation strategy used in this work is the born-dead-elements technique $[6,8]$. It classifies the
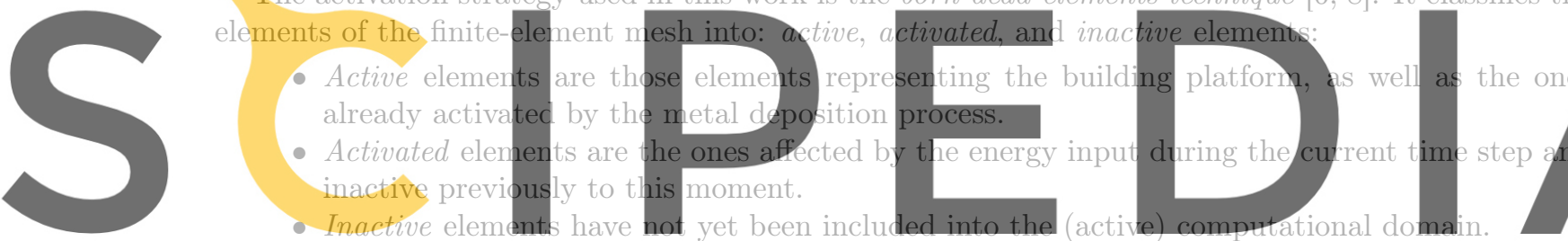

According to this, the computational domain is defined by the set of active and activated elements,

3.1. Space and time discretization of the heat source. The representation of the heat source within the FE framework is detailed in [8]. The melt pool moves from a given position $\mathbf{x}^{n}$ to the following position $\mathrm{x}^{n+1}$ in the interval $\Delta \mathrm{t}=\mathrm{t}^{n+1}-\mathrm{t}^{n}$ according to the predefined scanning sequence.

The total volume affected by the power input $\mathrm{V}_{\text {pool }}^{\Delta \mathrm{t}}$ in this interval, referred to as the Heat Affected Volume (HAV), can be represented as a cuboid of length $\mathrm{v}_{s} \Delta \mathrm{t}$, being $\mathrm{v}_{s}$ the scanning speed, and cross-section given by the average laser spot size $w_{\text {pool }}$, and the average layer thickness $L T$, as shown in Figure 4(b). The heat source term $\dot{\mathrm{r}}$ in Equation (1) is only applied to the elements inside the HAV.

At each time step, these elements are found with an octree-based search algorithm. If an inactive element belongs to the HAV, then it is activated. The volume of the melt-pool is computed as

$$
\mathrm{V}_{\text {pool }}^{\Delta \mathrm{t}, \mathrm{h}}=\sum_{(e) \in H A V} \mathrm{~V}^{(e)}
$$

and the (average) density distribution from the heat source is computed as

$$
\dot{\mathrm{r}}=\frac{\eta W}{\mathrm{~V}_{\text {pool }}^{\Delta \mathrm{t}, \mathrm{h}}},
$$

where $W$ is the laser power [watt] and $\eta$ is the heat absorption coefficient, a measure of the laser efficiency. This power redistribution preserves the total energy input, regardless of the FE mesh employed. 
The same care devoted to estimate the energy delivered by the laser beam must be placed to compute the heat dissipated through the boundaries of the computational domain. For this reason, another search procedure is used to update the contour surface at each time step of the simulation, in order to update the current boundary surfaces subject to heat radiation and convection $\left(\Omega_{e}\right)$ and heat conduction through the powder bed $\left(\Omega_{p}\right)$.

One of the added features of this FE activation technique is the possibility of specifying the scanning path using the same input data as for the process machine, for instance, with a Common Layer Interface (CLI) file format $[8,39]$. A CLI file describes the movement of the laser in the plane of each layer with a complex sequence of polylines, to define the (smooth) boundary of the component, and hatch patterns, to fill the inner section.

This is a great advantage because it simplifies the end-user work, when integrating the machine directives with the software interface. However, the scanning path only defines the sequence of points along which the power input moves, as well as the reference plane where the laser beam is focused. The scanning path does not contain any information regarding the velocities of the laser, the size of the melt pool, the spot-size of the laser or the thickness of the deposited layer. These values must be separately specified by the end-user.

3.2. Definition of scanning strategy. As seen in Figure 4(b), during a time increment the laser moves $\Delta \mathrm{x}=\left|\mathrm{x}^{n+1}-\mathrm{x}^{n}\right|=\mathrm{v}_{s} \Delta \mathrm{t}$ along the scanning path. From the end-user point of view, it is more convenient to prescribe $\Delta x$, instead of $\Delta t$, and let the software compute the time discretization as $\Delta t=v_{s} / \Delta x$. In this manner, different approximations of the scanning path, i.e. scanning strategies

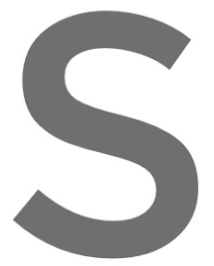
can be defined according to the
For instance, taking $\Delta x \approx h$
of the scanning path, an element-
Alternatively, the simulation can
hatches or even a whole layer.
fields, being not able to capture
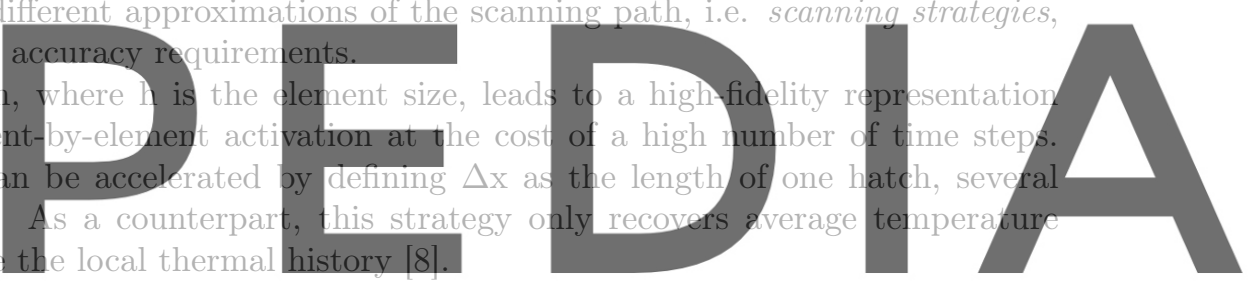

The choice of the scanning strategy depends on the target AM simulation. A high-fidelity approach

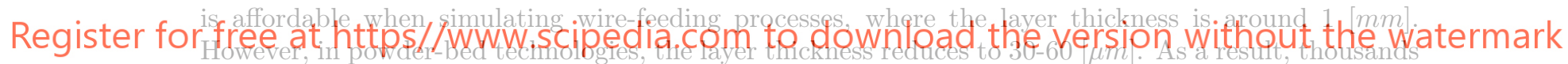

of layers of material must be added to build an industrial part and the high-fidelity strategy results in unreasonable computational times. In this case, hatch-by-hatch or layer-by-layer depositions should be considered.

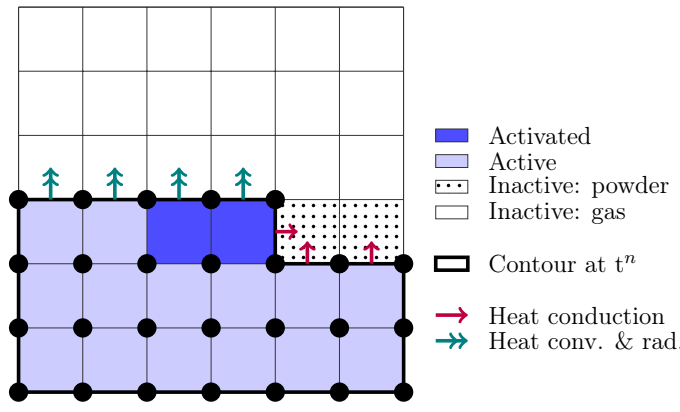

(A) As shown with this 2D FE cartesian grid, at each time step of the AM simulation, the computational domain is split into active, activated and inactive elements.

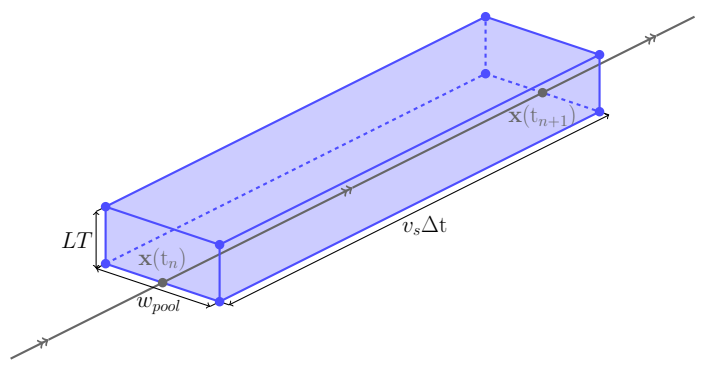

(в) Heat affected volume in powder-bed technologies. For a given time step, the laser source moves from position $\mathbf{x}^{n}$ to $\mathbf{x}^{n+1}$, according to the predefined scanning path.

FIGURE 4. FE activation technology: element classification and heat affected volume. 

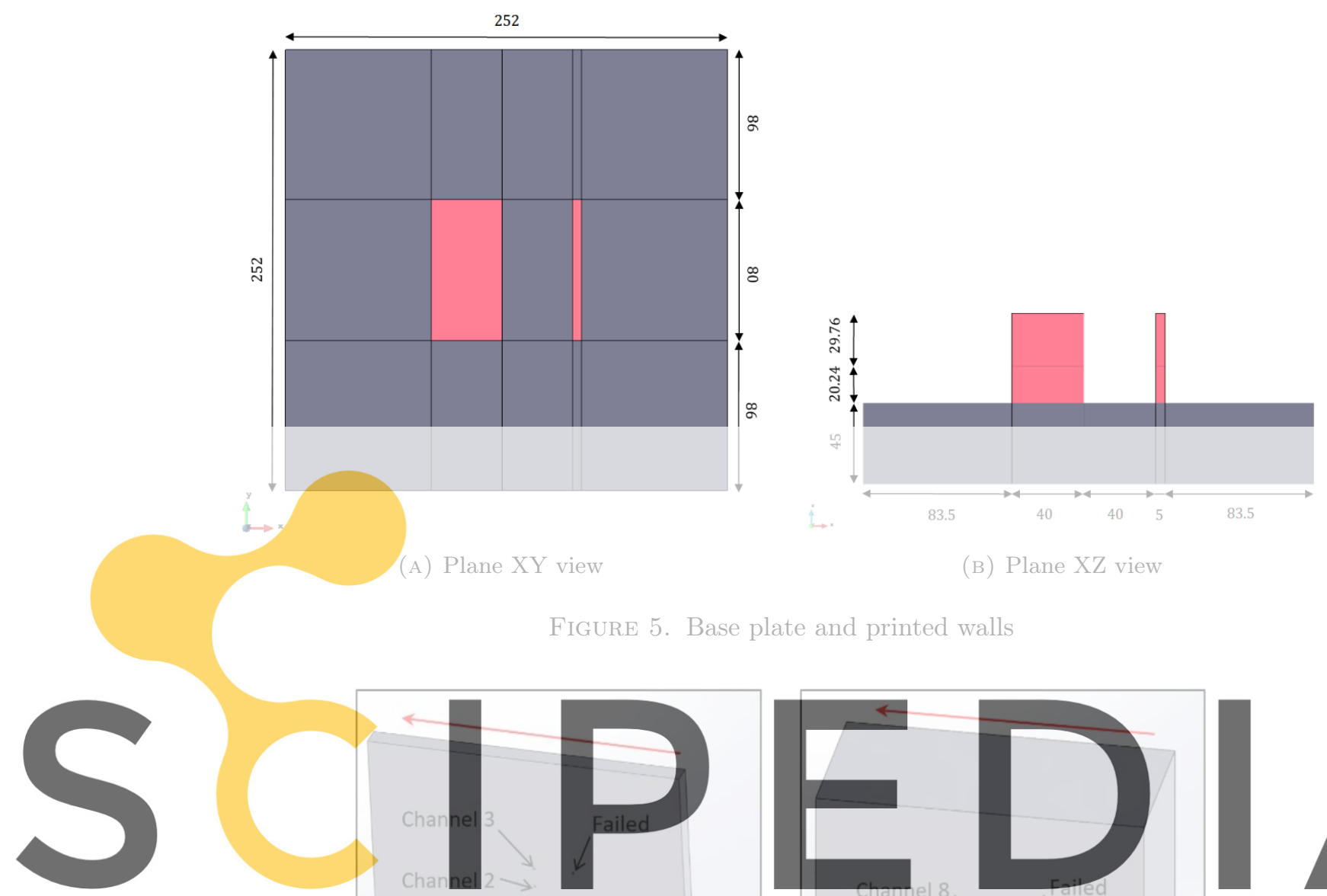

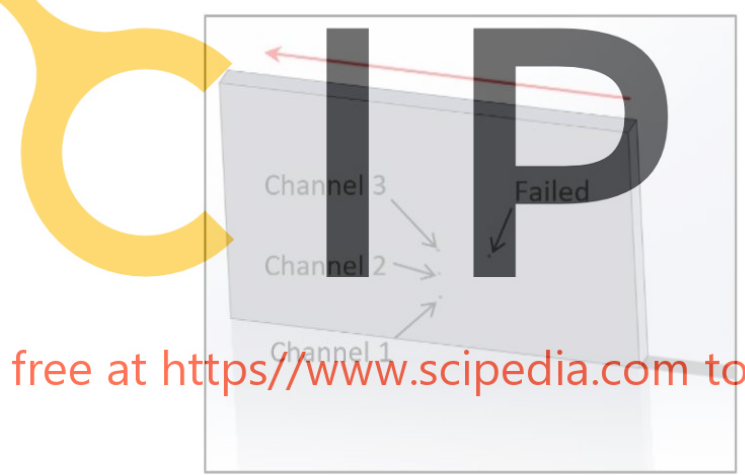

(A) Thermocouples at thin wall

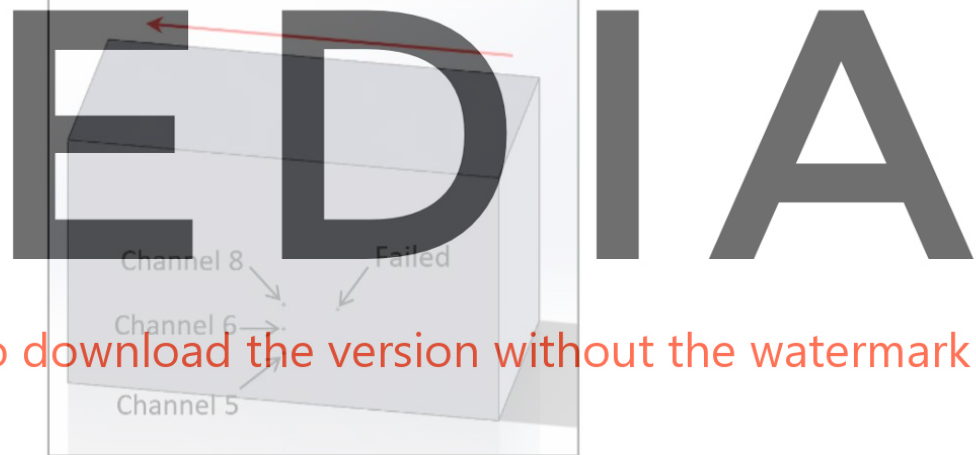

(в) Thermocouples at thick wall

FIGURE 6. Location of thermocouple channels

\section{EXPERIMENTAL CAMPAigN}

An experimental campaign is carried out at the Monash Centre for Additive Manufacturing (MCAM) in Melbourne, Australia, with the purpose of calibrating the thermal analysis FE framework described in Section 2 for powder-bed methods.

The printing system employed for the experiments is the EOSINT M280 from Electro Optical Systems (EOS) GmbH. It makes use of an Yb-fibre laser with variable beam width and power up to $400[\mathrm{~W}]$. The printing process is carried out in a closed 250x250x325 $\left[\mathrm{mm}^{3}\right]$ chamber in a controlled argon atmosphere to prevent oxidation of the part. The argon flow is kept laminar.

Figure 5 shows the samples geometry for the numerical calibration. These consist of two specimens printed simultaneously: a thin wall measuring $5 \times 80 \times 50\left[\mathrm{~mm}^{3}\right]$ and a thicker wall measuring 40x80x50 $\left[\mathrm{mm}^{3}\right]$. The two walls are separated by a distance of $40[\mathrm{~mm}]$. The base plate has dimensions of $252 \times 252 \times 45\left[\mathrm{~mm}^{3}\right]$. Ti64 powder is used for the printing operation.

The thermocouples for the temperature measurements are inserted into holes at different locations of the two specimens. For this purpose, the printing job has to be interrupted after an initial deposition 

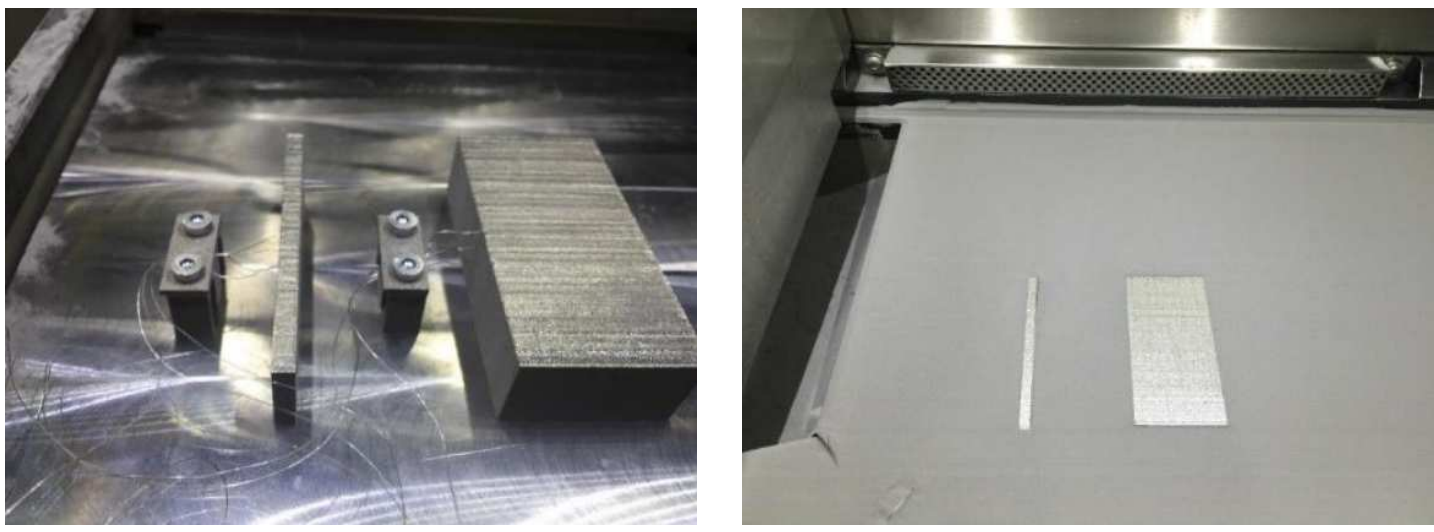

(A) The printing job is interrupted at $20.24[\mathrm{~mm}]$ height, the powder bed is removed, and four ther-

(B) The powder bed is restored and the printing job was resumed. mocouples are inserted into holes of each sample.

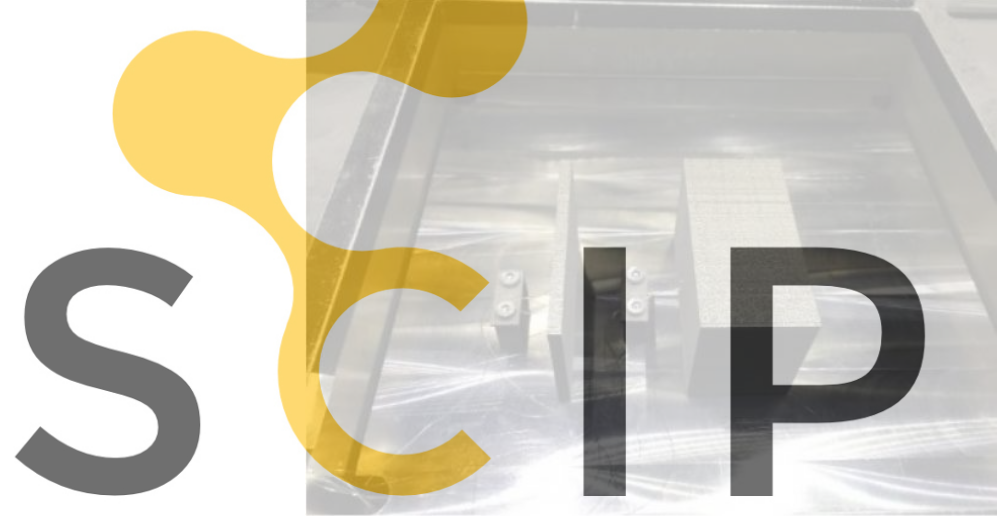

(C) After finishing the printing job, the powder

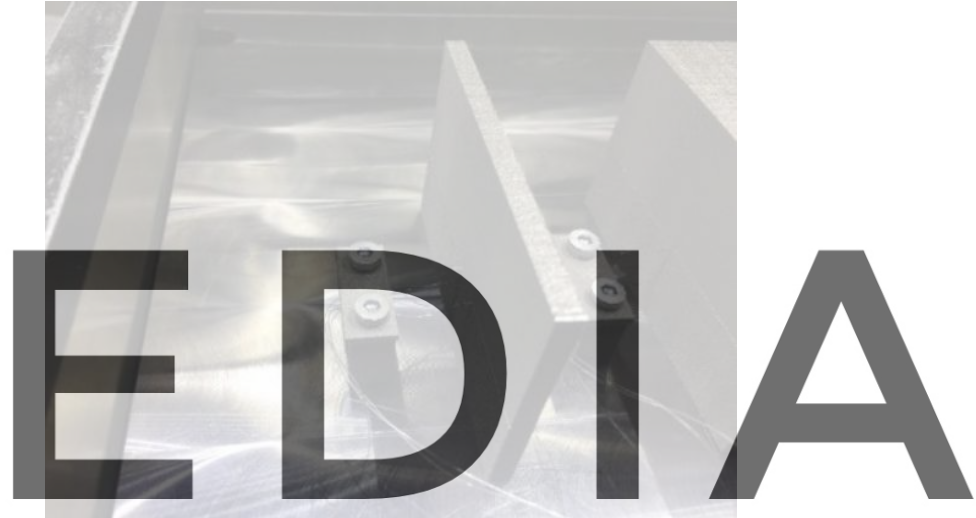

(D) A closer picture shows the position of the ther-

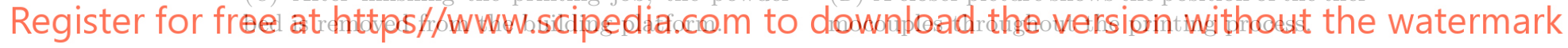

FigURE 7. Steps to carry out the temperature measurements

of 20.24 [mm] high and the powder bed has to be removed. Four thermocouples are installed in each sample: the first three separated by $5[\mathrm{~mm}]$ in the vertical direction and the fourth one displaced 10 [mm] horizontally from the top one, as shown in Figure 6. Next, the powder bed is restored, and the scanning sequence resumed, as described in Figure 7. As thermocouples are not welded, their measurements can be affected by air trapped in their holes.

K-type thermocouples and a Graphtec GL-900 8 high-speed data-logger are used for the data gathering. Temperature data could be measured only from six channels, because the fourth channel in both walls was broken during the setup operations. The sampling rate of the data logger is 1 [ms] and the time constant of the thermocouples is 7 [ms].

Table 1 shows the process parameters used for the printing process. As observed, the layer thickness is set to $30[\mu \mathrm{m}]$, meaning that 992 layers are deposited in about 33,500 s (a little bit more than 9h) to build the samples.

A unidirectional scanning strategy is applied along the longitudinal direction of both samples. In Figure 8 the scanning sequence used for the printing process is described. The scanning path alternates between odd and even layers. Note that the number of hatches drawn does not correspond to the actual number of hatches, which is notably higher according to the power beam size.

The printed samples are made of Ti6Al4V Titanium alloy. The temperature-dependent properties of the bulk material, covering the range from room temperature to fusion temperature, are depicted 

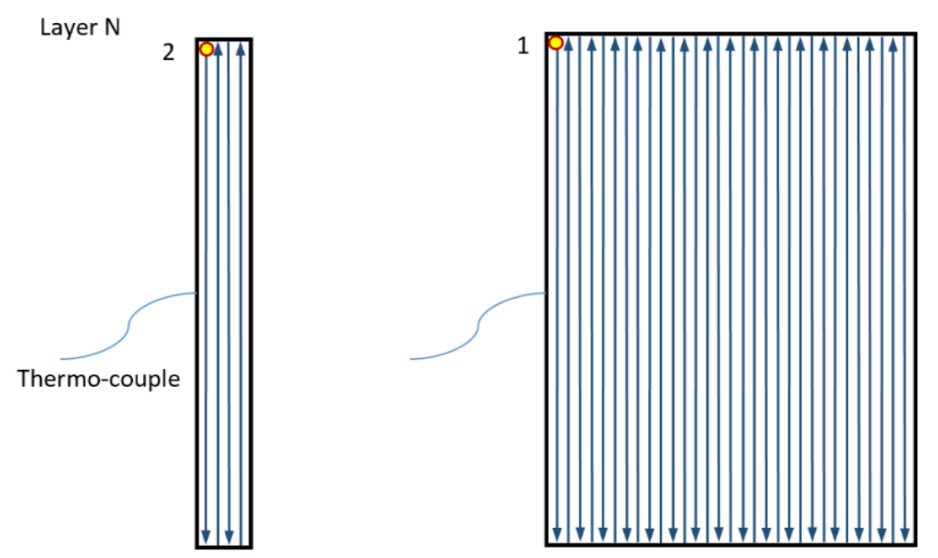

(A) Pattern for odd layers. Starting points are indicated with circles.

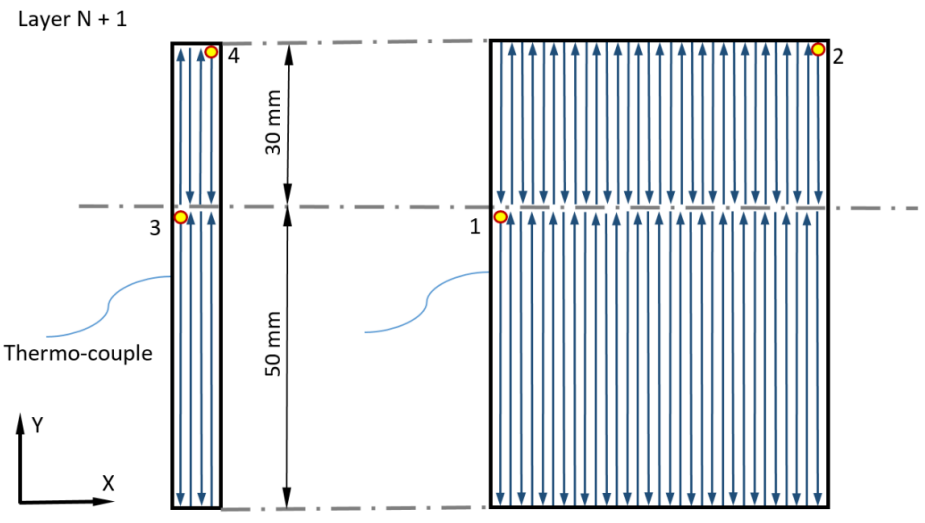

(в) Pattern for even layers. Starting points are indicated with circles.

Figure 8. Base plate and printed walls

\begin{tabular}{|c|cc|}
\hline Power input & 280 & {$[\mathrm{~W}]$} \\
\hline Scanning speed & 1200 & {$[\mathrm{~mm} / \mathrm{s}]$} \\
\hline Layer thickness & 30 & {$[\mu \mathrm{m}]$} \\
\hline Hatch distance & 140 & {$[\mu \mathrm{m}]$} \\
\hline Beam offset & 15 & {$[\mu \mathrm{m}]$} \\
\hline Recoat time & 9.36 & {$[\mathrm{~s}]$} \\
\hline Relocation time & 0.03 & {$[\mathrm{~s}]$} \\
\hline
\end{tabular}

TABLE 1. Process parameters adopted by the EOS Machine

in Figure 9. The base plate is made of $\mathrm{CP} \mathrm{Ti}$, a material with similar thermal properties as those of Ti64.

Complementary experiments were done to estimate the density of the porous bed, as it is formed layer-by-layer during the printing process. According to these measurements, the packing density is about $2405[\mathrm{~kg} / \mathrm{m} 3]$ at room temperature. Thus, the relative density of Ti64 powder is around $54 \%$, with respect to the density of the bulk material at room temperature.

\section{Numerical Results AND Discussion}




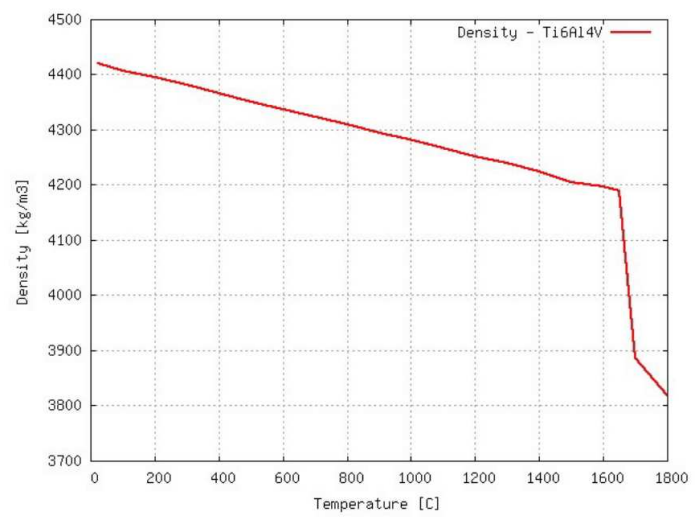

(A) Density

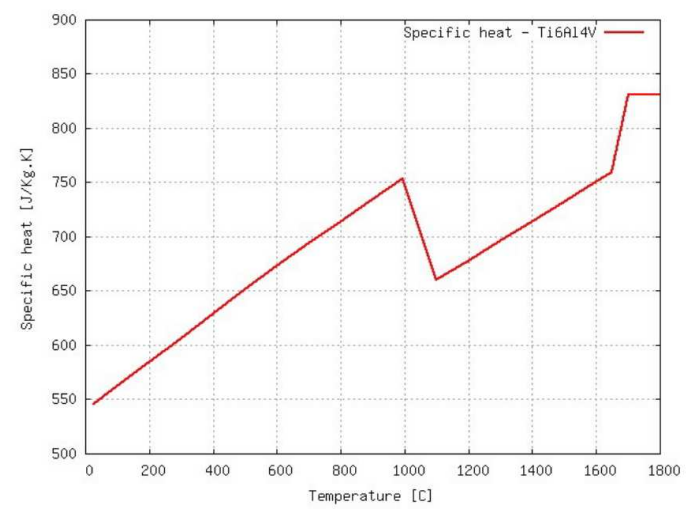

(в) Specific heat

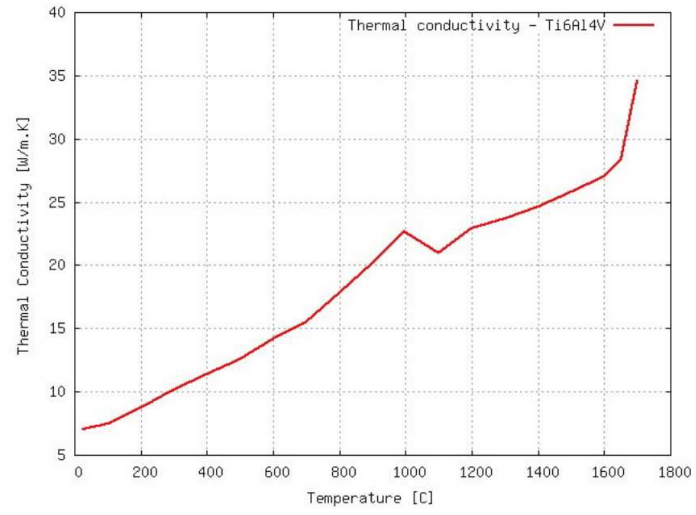

(c) Thermal conductivity

Figure 9. Ti6Al4V Titanium alloy thermal bulk material properties

5.1. Initial calibration of the model. The in-house research software COupled MEchanical and Thermal (COMET) [4] is suitably enhanced to provide a FE framework for the heat transfer analysis of AM by powder-bed technologies. The model is calibrated against the experimental data obtained at the MCAM research centre.

The numerical model selected for the calibration procedure should reproduce as close as possible the physical process. Likewise, the size of the simulation should be chosen to enable a full sensitivity analysis in reasonable computational times. 


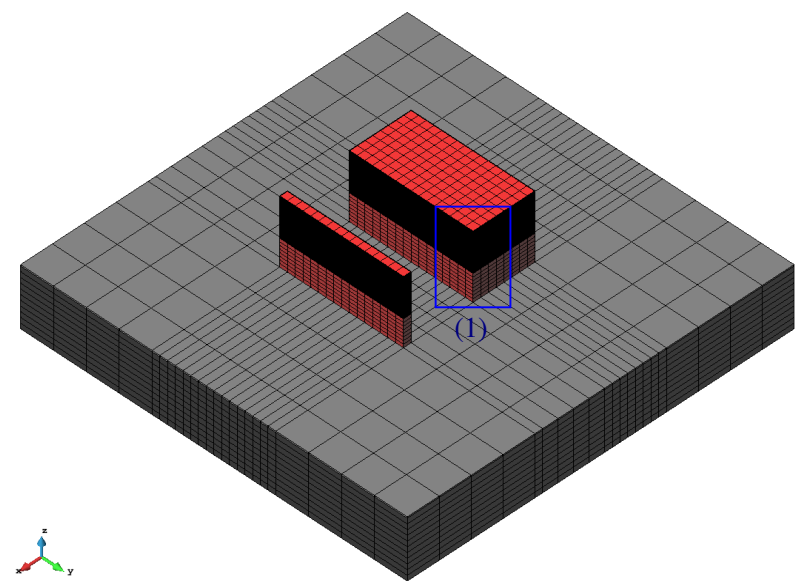

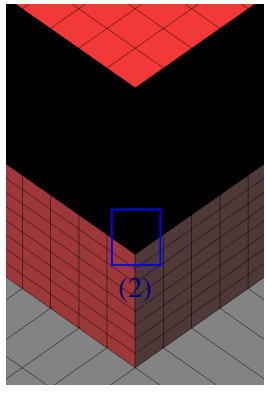

(1)

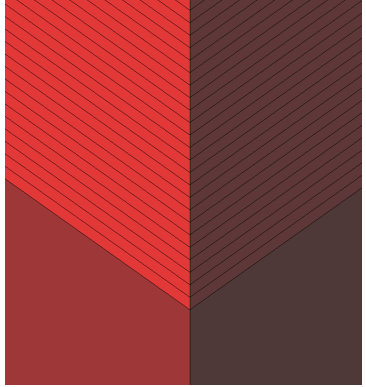

(2)

Figure 10. The FE mesh conforms to the layers, as seen in the close-up plots.

For the most accurate simulation of the metal deposition, the FE mesh must conform to the printed layers, the mesh size must be smaller than the laser beam spot size, and the scanning path must be tracked element by element. However, meeting these requirements in this experiment is extremely difficult from the computational point of view. For instance, assuming a uniform mesh with element size $50 \times 50 \times 30[\mu \mathrm{m}]$, a single layer of the thick wall is composed of 1,280,000 elements to be printed in $1,280,000$ time steps.

For these reasons, in a first stage of the calibration process, the powder bed has been excluded from the analysis and the scanning path has been approximated to obtain a computationally affordable numerical model. On the one hand, these two assumptions have an impact on the accuracy, as discussed in Section 2.2.2 and Section 1, but it was the only possibility to perform the sensitivity analysis to calibrate the numerical model for the whole build process. On the other hand, the experimental measurements are perturbed by the air trapped in the thermocouple holes and the sampling rate of the data logger, which delays the thermocouple response when registering peak temperature values.

This given, the FE discretization consists of a structured mesh of 150,048 hexahedral elements and 194,150 nodes. Figure 10 shows the numerical model considered for the numerical simulation of the printing process. This model includes the building platform to account for the heat dissipation by conduction, but excludes the powder bed. Hence, the heat loss by conduction through the powder bed is modelled through the equivalent heat flux described in Section 2.

To further decrease the computational cost, the mesh size is adapted according to the different regions in the model. Small 5x5x0.03 mm elements are specified at the deposition regions, while a larger mesh size is specified below the deposition regions and the base plate. As a result of approximating the scanning path and using a uniform heat source distribution, the mesh size no longer needs to be smaller than the laser spot size to obtain an average thermal response with a relative error bounded by $10 \%$. It suffices that it conforms to the hatch width $(5 \mathrm{~mm})$.

The simulation starts when the printing job is resumed after placing the thermocouples and continues throughout the deposition of the remaining 992 layers, up to the cooling of the whole ensemble. Each new layer is printed in four steps:

(1) The scanning sequence corresponding to a new layer of the thin sample is performed;

(2) The laser moves from the thin sample to the thick sample (relocation time);

(3) The scanning sequence corresponding to a new layer of the thick sample is carried out;

(4) The platform is lowered and a new powder layer is spread. During the recoat time, the heat transfer analysis to account for the cooling process of the samples is performed. 


\begin{tabular}{|c|cc|}
\hline Power input & 280 & {$[\mathrm{~W}]$} \\
\hline Power absorption & 45 & $\%$ \\
\hline Scanning speed & 2.10 & {$[\mathrm{~mm} / \mathrm{s}]$} \\
\hline Back speed & 12.40 & {$[\mathrm{~mm} / \mathrm{s}]$} \\
\hline Layer thickness & 30 & {$[\mu \mathrm{m}]$} \\
\hline Hatch width & 5 & {$[\mathrm{~mm}]$} \\
\hline
\end{tabular}

TABLE 2. Process parameters used in the hatch-by-hatch strategy

The building platform is kept at $100\left[{ }^{\circ} \mathrm{C}\right]$ during the whole printing process. The average temperature of the powder, as well as the temperature inside the chamber, used for the calibration of the heat transfer coefficients (heat loss by convection and radiation), are set to constant values of $83\left[{ }^{\circ} \mathrm{C}\right]$ and $35\left[{ }^{\circ} \mathrm{C}\right]$, respectively, according to on-site measurements.

The HTC for the heat convection model is calibrated to $1.0\left[\mathrm{~W} / \mathrm{m}^{2} \mathrm{~K}\right]$. The powder conductivity required to deal with the heat dissipation through the powder bed is obtained taking $k_{T i 64}=7[\mathrm{~W} / \mathrm{mK}]$ and $k_{\text {argon }}=0.016[\mathrm{~W} / \mathrm{mK}]$ at $20\left[{ }^{\circ} \mathrm{C}\right]$. Hence, according to Equation $(8), k_{p}$ results in about 0.14 $[\mathrm{W} / \mathrm{mK}]$. Repeating the evaluation at $800\left[{ }^{\circ} \mathrm{C}\right]$, the resulting $\mathrm{HTC}$ is $k_{p}=0.60[\mathrm{~W} / \mathrm{mK}]$. Hence, according to the average temperature of the powder, the powder conductivity used for the simulations is $k_{p}=0.20[\mathrm{~W} / \mathrm{mK}]$. Furthermore, $s_{p}=40[\mathrm{~mm}]$, leading to an equivalent HTC by conduction of $h_{p}$ $=5.0\left[\mathrm{~W} / \mathrm{m}^{2} \mathrm{~K}\right]$.

Figure 12 describes the experimental data gathered at the six working thermocouples at both samples. The two samples have very different thermal modulus, that is, the ratio between the volume and the area of the external surfaces to dissipate the heat in the surrounding environment. This explains why the thick sample, with higher thermal modulus, presents higher temperatures than the thinner sample.

Regarding the evolution in time, it starts with a temperature build-up that stabilises at about the hundredth layer. Afterwards, the temperature at the thermocouples decreases slowly until the end of the printing stage, when it drops until cooling down to the initial temperature. This quasi steadystate regime in the middle of the process is a result of the thermocouples being far from the HAZ, i.e. thermal gradients in the neighbourhood are small, and it can be clearly identified here due to the long duration of the experiment, as opposed to the short experiments predominant in the literature.

Apart from that, it can be noticed how the temperature measurements recorded at the thermocouples $\mathrm{CH} 3$ and $\mathrm{CH} 8$ present extremely high oscillations at the beginning of the process. This is due to the heat radiation during the deposition of the first layers, after resuming the printing process. For this reason, only the data from thermocouples $\mathrm{CH} 1$ and $\mathrm{CH} 2$ (thinner sample) and thermocouples $\mathrm{CH} 5$ and $\mathrm{CH} 6$ (thicker sample) are accounted for the calibration process.

The sensitivity analysis has been performed using the following simplified scanning strategy, referred to as hatch-by-hatch:

(1) One single hatch is used for the layer sintering of the thin sample in a single time step. The total amount of energy input used is uniformly spread at once.

(2) Next, the laser source is moved from the thin to the thick sample ready for the following sintering process. The model is allowed to cool down during this relocation time.

(3) Later, the layer sintering of the thick sample is performed using 8 hatches, $5[\mathrm{~mm}]$ wide, in 8 time steps.

(4) During the final recoat and relocation phases, a new layer of powder is spread and the corresponding cooling process is accounted for.

Steps 1 to 4 are repeated until completion of the building process. Finally, the cooling process to the room temperature is analysed.

The hatching pattern of this simulation strategy is described in Figure 11(a). The process parameters used for the numerical simulation are gathered in Table 2. The scanning speed (printing) and the back speed (relocation, recoat) have been adapted to match the values in Table 1. 
Thermocouples $\mathrm{CH} 1$ and $\mathrm{CH} 2$ have been used as target to get the most suitable simulation parameters to catch the experimental evidence. In particular, they have been used to calibrate both the power absorption coefficient (responsible of the power input into the system) and the equivalent HTC between the samples and the powder bed (controlling the heat loss through the external surfaces of the components).

Figure 13 compares the numerical results with the experimental measurements at $\mathrm{CH} 1$ and $\mathrm{CH} 2$. A very good agreement can be observed in the thermal response. The only mismatch is detected during the final cooling process, while cooling down to the room temperature.

A similar but slightly lower accuracy of the numerical model can be observed in Figure 14 when comparing the results obtained for the thick sample. This can be attributed to the approximation of the heat loss model through the powder bed. In particular, assuming a uniform value for the powder temperature is not fully reliable (e.g. between the two samples there should be a higher value than the average value used for the entire model). Nevertheless, this mismatch is less than $10 \%$.

5.2. Numerical model assessment. In a next stage, a set of numerical tests is carried out to test the previous hypotheses and investigate different numerical strategies to simulate the AM process by powder-bed methods. The objective is to find the best compromise between computational cost and accuracy.

First, the powder bed is added to the model. In this case, the size of the FE discretization is much bigger, including 594,368 hexahedral elements and 649,230 nodes. This model is about six times bigger than the previous one (without powder bed) and the simulation time is almost four times longer (from 1 day to about 4 days). The thermophysical properties of the Titanium powder are obtained as defined in Section 2, with the values of porosity and thermal conductivity listed in Table 3.

Figure 15 compares the numerical results with and without including the powder bed in the simulation. The results are not as good as in the previous case, even if the model is more realistic. This is due to several reasons: (1) the results strongly depend on the thermophysical properties used to characterise the metal powder: density, specific heat and conductivity, all of them should be defined in terms of the actual temperature field. The available limited characterisation of the powder made difficult their calibration; (2) the much higher computational cost made extremely slow the sensitivity analysis.

Besides, this simulation is useful to examine the values of $s_{p}$ and the average temperature of the powder. Figure 19 shows that $s_{p}$ is around $40[\mathrm{~mm}]$ and the powder temperature is $83\left[{ }^{\circ} \mathrm{C}\right]$. However, it is also evident that the average temperature of the powder between the two samples should be approximately $135\left[{ }^{\circ} \mathrm{C}\right]$, instead of $83\left[{ }^{\circ} \mathrm{C}\right]$.

The next numerical simulations are intended to assess different scanning strategies. First, a layerby-layer building strategy has been selected to reduce as much as possible the simulation time, while providing reasonable accuracy. Hence:

(1) One single time step is used to add simultaneously a new layer for both samples. The energy density used is spread homogeneously at once. The sintering time includes the relocation time, that is, the time used by the laser to move from the ending point of the scanning sequence at thin sample to the starting point at the thick sample.

(2) Further time steps are performed to account for the cooling process during the recoating and relocation times, when the building platform is lowered and a new layer of powder is spread.

(3) The discretization of the powder bed is avoided.

Steps 1 and 2 are repeated until completing the building process. Later, the cooling process to the room temperature ends the analysis. The scanning pattern of this simulation strategy is described in Figure 11(b). The new values of the scanning speed and the back speed are gathered in Table 4 .

Similarly, a multi-layer-by-multi-layer simulation strategy can be considered for further reduction of the computational cost. In Figure 16, the numerical results with both layer-by-layer and 4-layerby-4-layer strategies are compared with the hatch-by-hatch result taken as a reference.

Observe that, when using a layer-by-layer strategy, the corresponding energy density is spread uniformly. Hence, the temperature plots must be intended as an average evolution of the temperature 


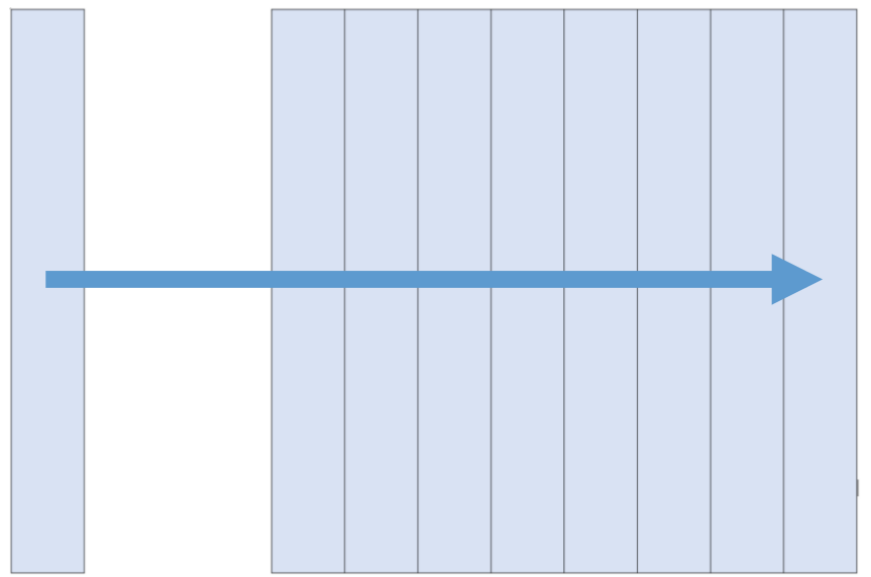

(A) Hatch-by-hatch: Each layer is printed using $1+8$ hatches.

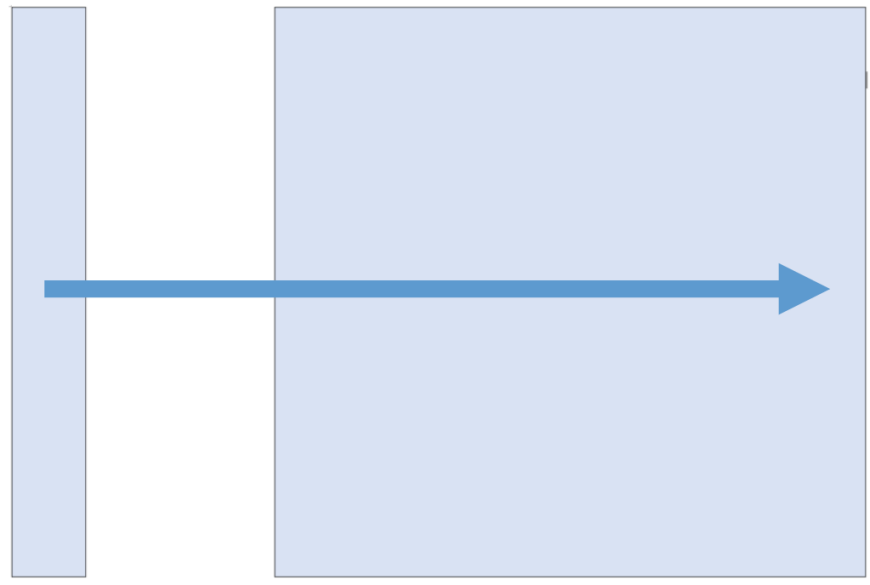

(в) Layer-by-layer: A new layer for the thin and the thick sample samples is simultaneously deposited in a single time step.

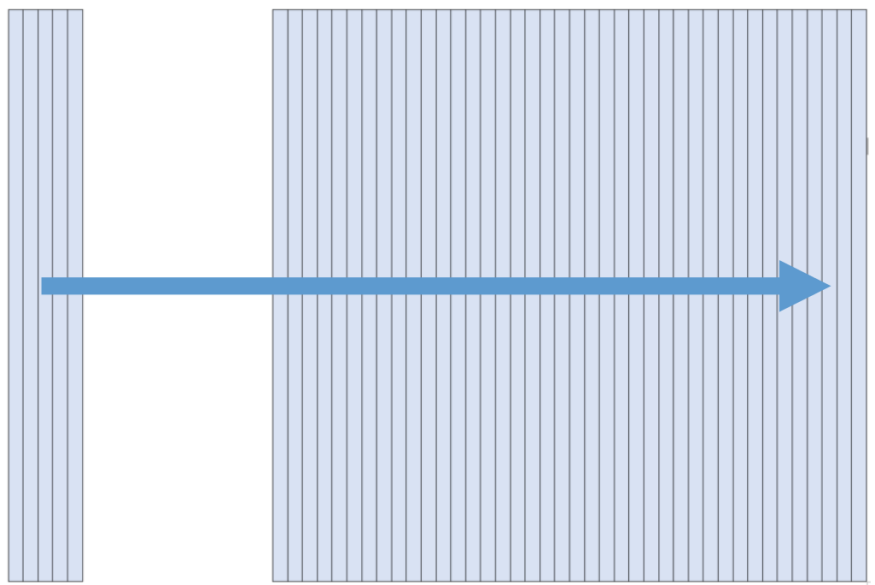

(c) High-fidelity: the hatch width is reduced to $1[\mathrm{~mm}]$.

FiguRE 11. Different scanning strategies were considered in the numerical analysis. 


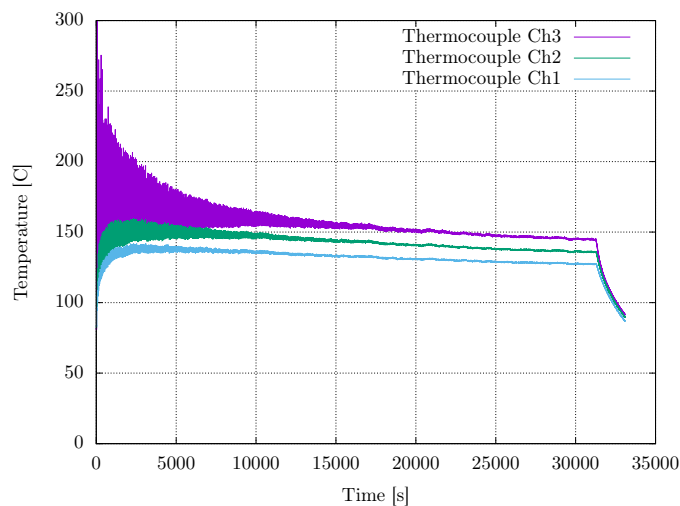

(A) Measured data at thin sample

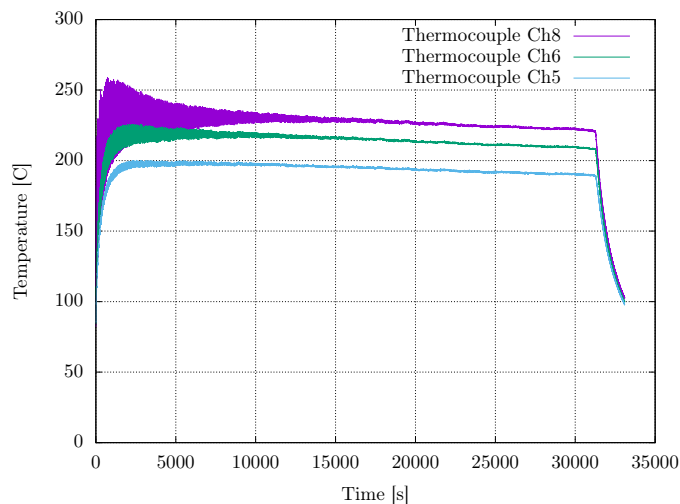

(B) Measured data at thick sample

FiguRE 12. Experimental data gathered for both sample locations

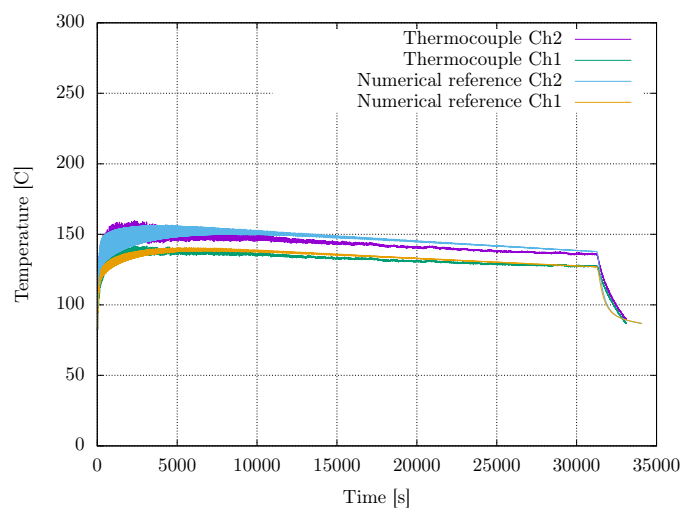

(A) The entire sintering process

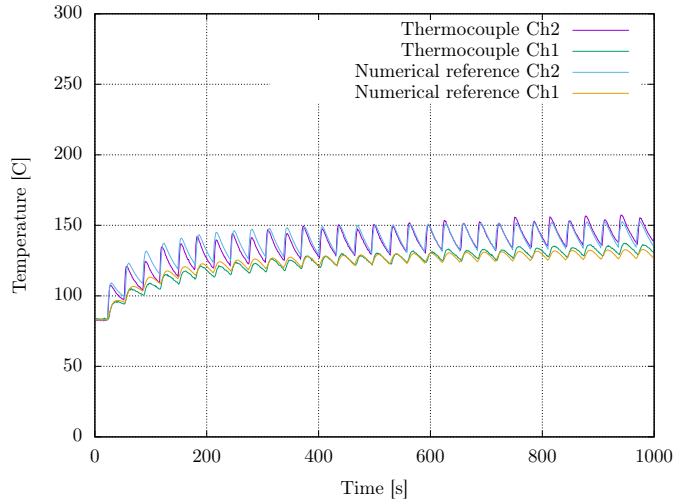

(в) The first phase after resuming the build job

FIGURE 13. Hatch-by-hatch (reference): Numerical results at the thin sample

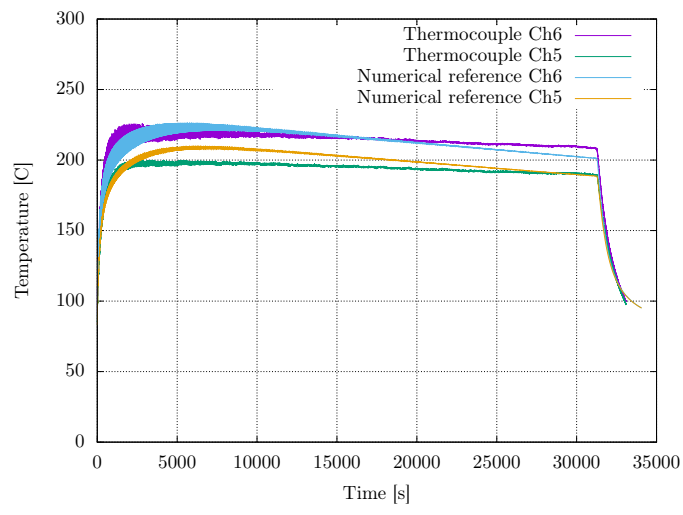

(A) The entire sintering process

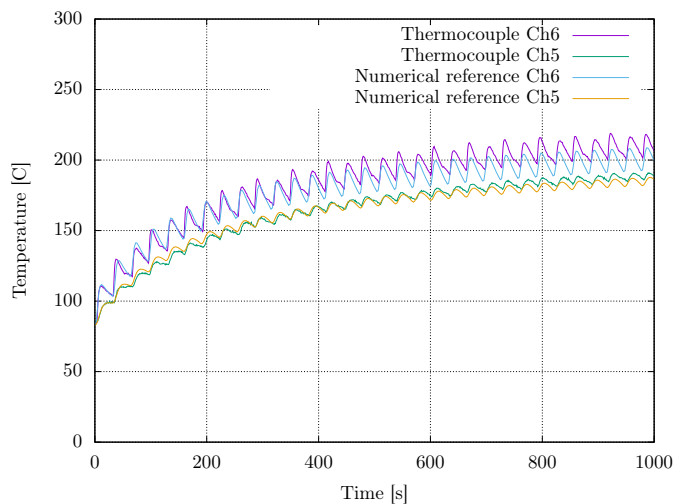

(B) The first phase after resuming the build job

FiguRE 14. Hatch-by-hatch (reference): Numerical results at the thick sample 


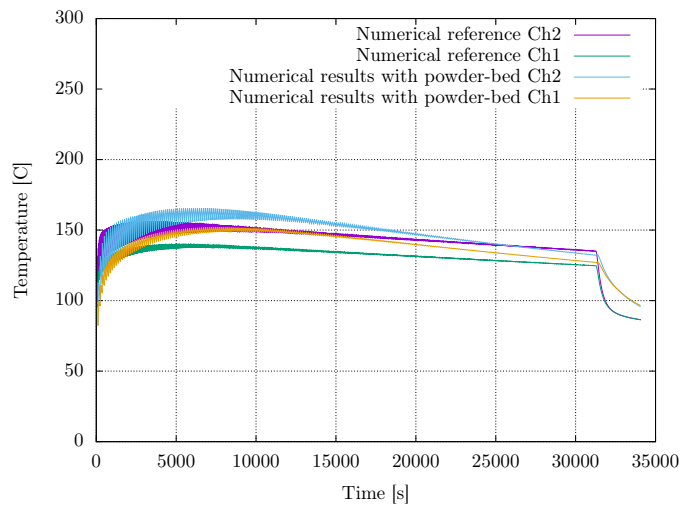

(A) At the thin sample

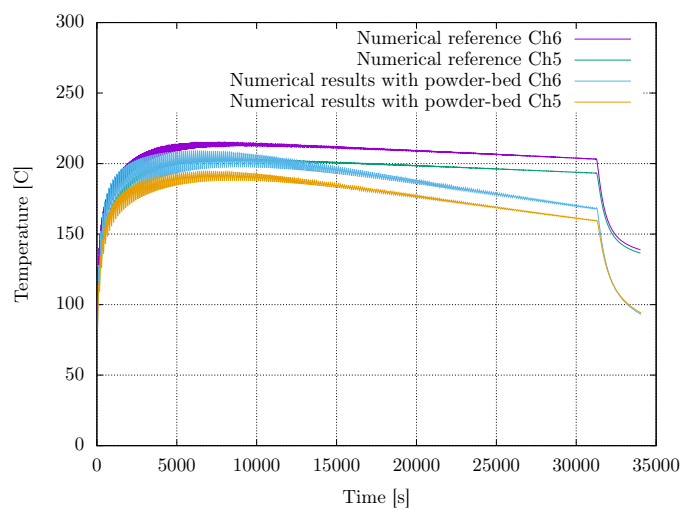

(B) At the thick sample

FiguRE 15. Numerical results with or without (reference) including the powder bed into the computational domain

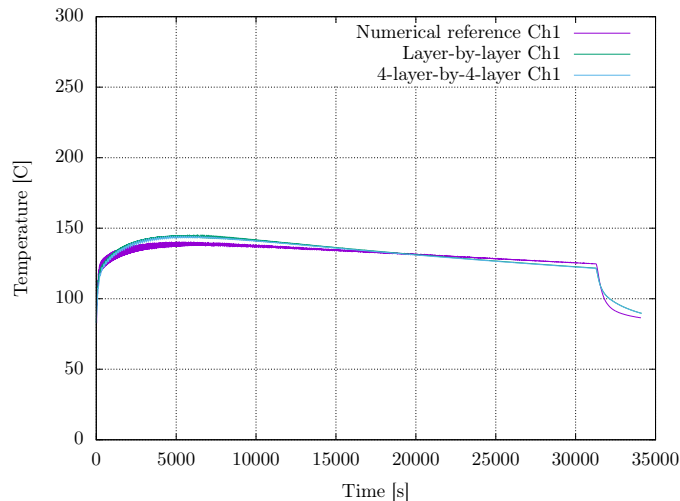

(A) The entire sintering process

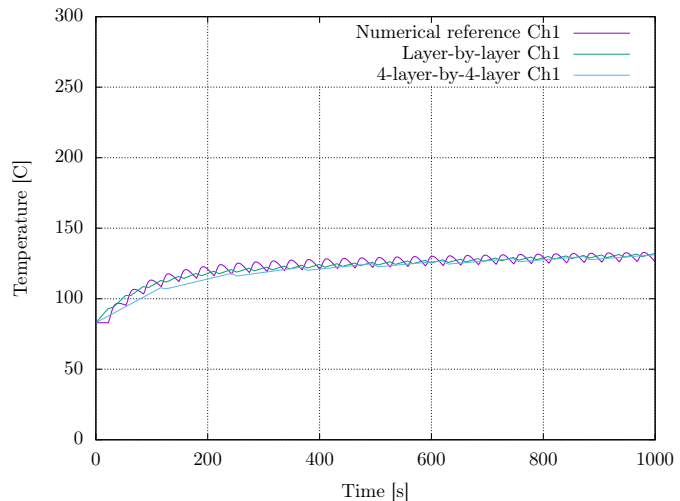

(в) The first phase after resuming the build job

FIGURE 16. Numerical results obtained by layer-by-layer and 4-layer-by-4-layer strategies

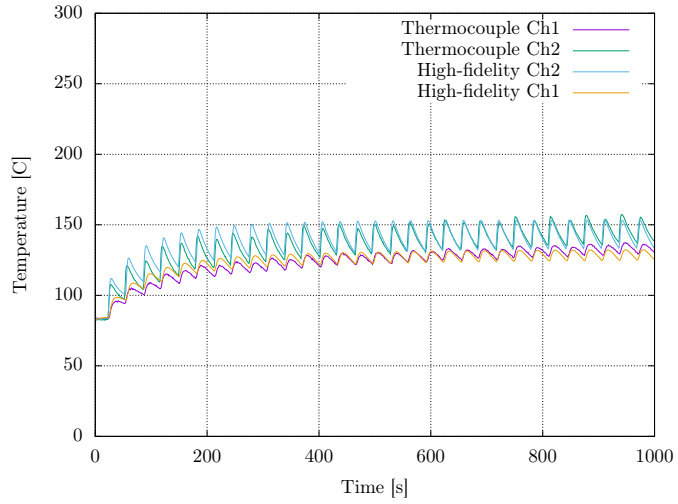

(A) Comparison with experimental data

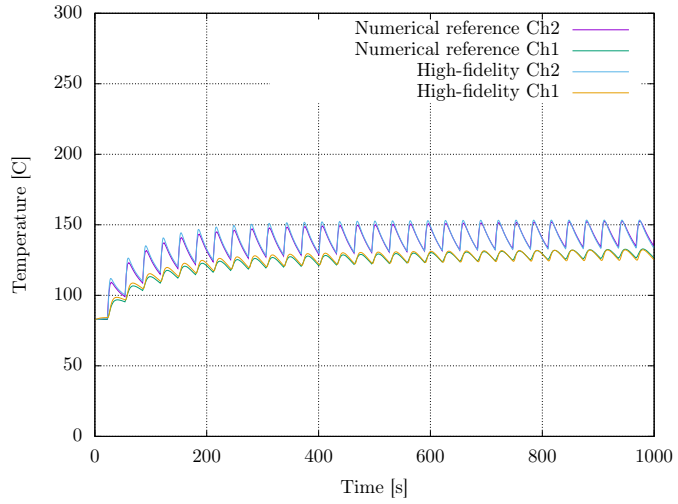

(B) Comparison with numerical reference

FiguRE 17. Numerical results obtained with a high-fidelity simulation 


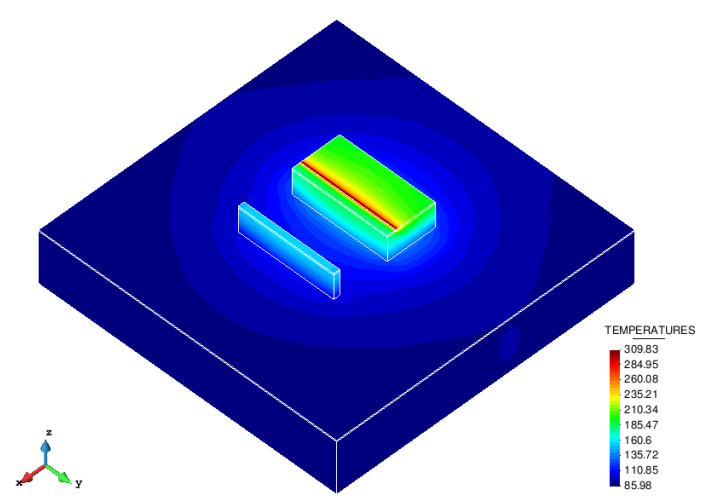

(A) High-fidelity strategy

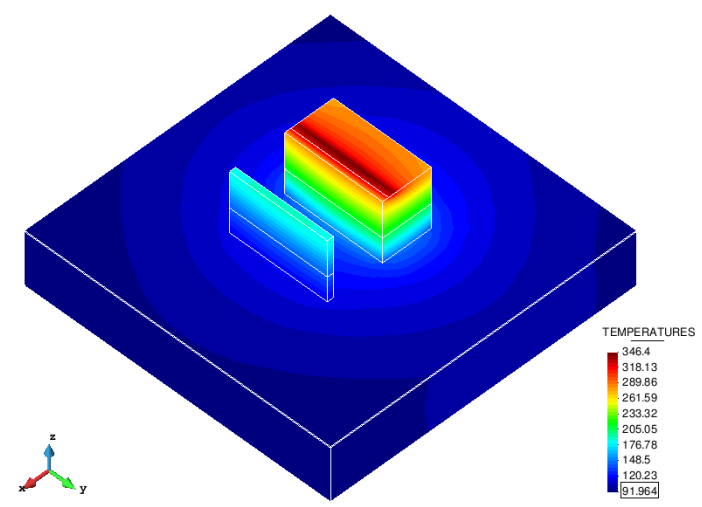

(c) Hatch-by-hatch strategy

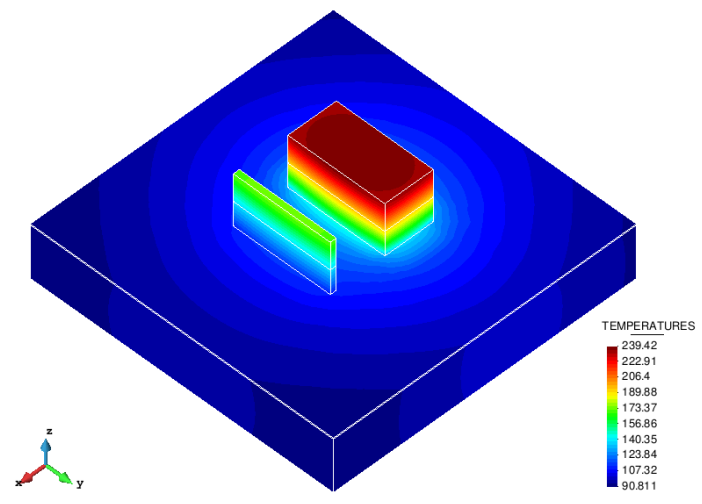

(E) Layer-by-layer strategy

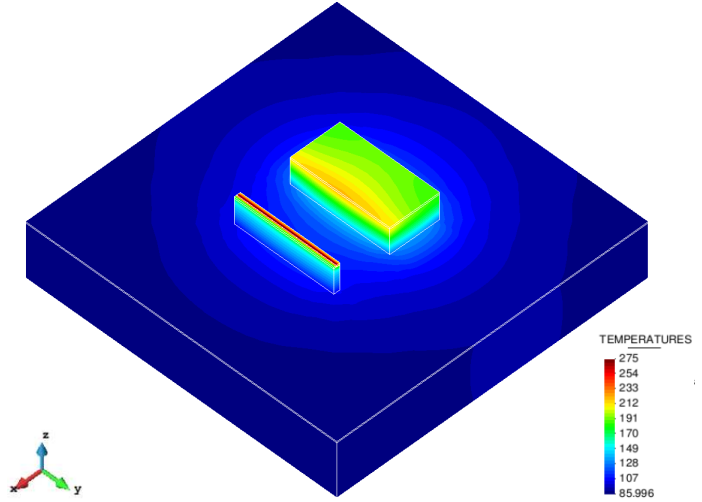

(в) High-fidelity strategy

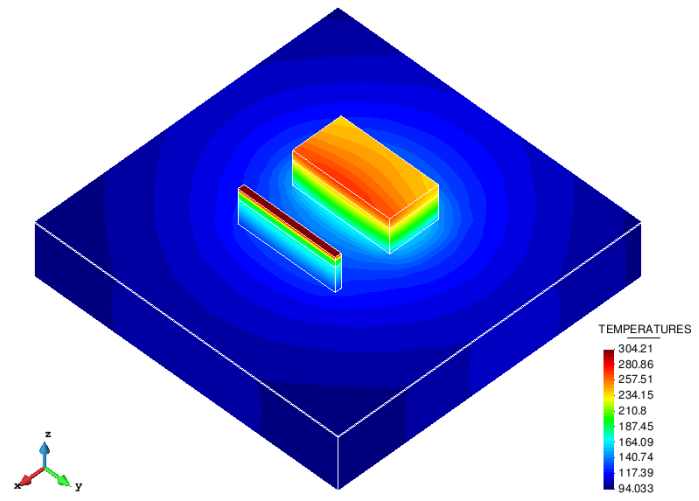

(D) Hatch-by-hatch strategy

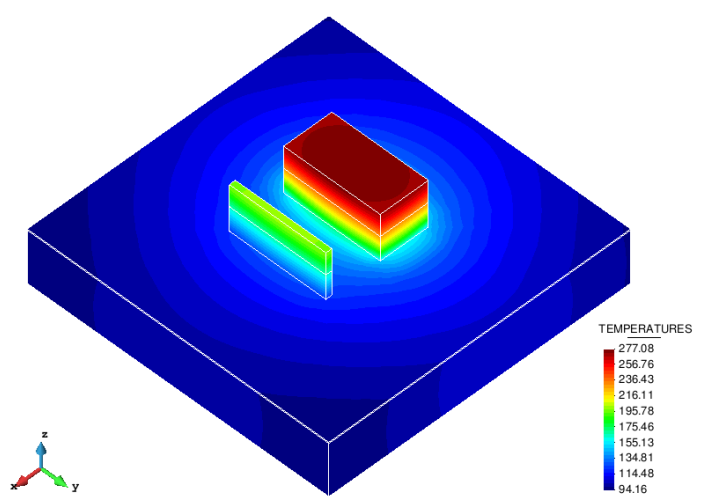

(F) 4-layer-by-4-layer strategy

FiguRE 18. Contour plots of temperatures for the analysed scanning strategies at different time steps. The locality of the temperature distribution decreases as the scanning path simplifies.

\begin{tabular}{|c|cc|}
\hline Porosity & 46 & $\%$ \\
\hline Thermal conductivity & 0.20 & {$[\mathrm{~W} / \mathrm{mK}]$} \\
\hline
\end{tabular}

TABle 3. Porosity and thermal conductivity of the Titanium powder 


\begin{tabular}{|c|cc|}
\hline Scanning speed & 3.73 & {$[\mathrm{~mm} / \mathrm{s}]$} \\
\hline Back speed & 0.69 & {$[\mathrm{~mm} / \mathrm{s}]$} \\
\hline
\end{tabular}

TABLE 4. New process parameters for the layer-by-layer strategy

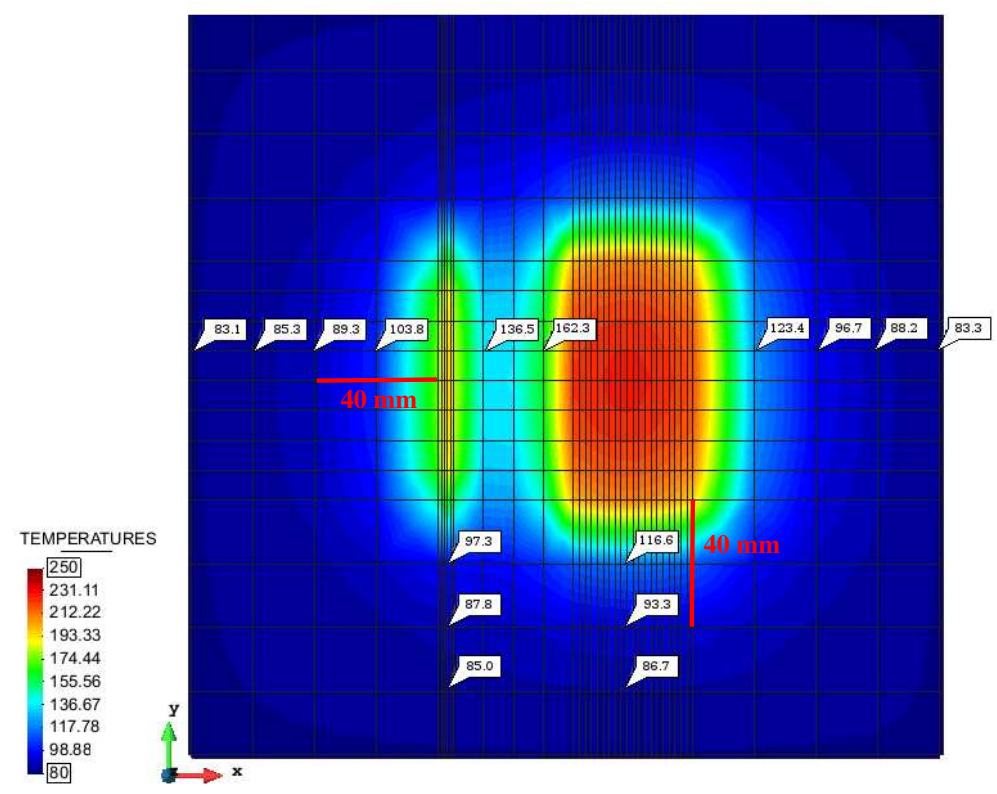

Figure 19. Contour plot of temperatures for the simulation including the powder bed. As assumed in the initial calibration stage, $s_{p}$ is around 40 [mm].

\begin{tabular}{|c|cc|}
\hline Strategy & CPU-time [h] & {$[\mathbf{\%}]$} \\
\hline Reference hatch-by-hatch & 24 & 100 \\
\hline Hatch-by-hatch with powder & 96 & 400 \\
\hline Layer-by-layer & 4 & 17 \\
\hline 4-layer-by-4-layer & 1.33 & 6 \\
\hline High-fidelity & 128 & 533 \\
\hline
\end{tabular}

TABLE 5. Simulation CPU times for the different scanning strategies analysed

field of the layer, with no direct relationship with the measurement locations. Clearly, the CPU-time is notably reduced when adopting the layer-by-layer strategy, as shown in Table 5 .

Finally, a further scanning strategy has been defined to be closer to the actual hatching sequence of the SLM machine. This new scanning pattern is depicted in Figure 11(c) and the resulting simulation strategy is referred to as high-fidelity. The process parameters used are the same as those in Table 2, except for the hatch width, which has a value of 1 [mm]. Figure 17 compares the high-fidelity results with the experimental data at thermocouple locations $\mathrm{CH} 1$ and $\mathrm{CH} 2$.

The similarities between the hatch-by-hatch and the high-fidelity scanning strategies is clear. However, the high-fidelity model required a computational time 5 times longer, if compared to the hatchby-hatch strategy: $32 \mathrm{~h}$ and $6 \mathrm{~h}$, respectively.

The assessment of the numerical model has given a better insight into the accuracy, computational cost, and applicability of the different model reduction techniques presented in this work: 


\begin{tabular}{|c|cccc|}
\hline Strategy & Accuracy & CPU-time & Applications & Build size \\
\hline $\begin{array}{c}\text { Mesh size } \approx \\
\text { Laser spot size }\end{array}$ & $\bullet \bullet \bullet \bullet \bullet$ & $\bullet \bullet \bullet \bullet \bullet$ & $\begin{array}{c}\text { Thermomechanical, mesoscale, and } \\
\text { microscale analyses. }\end{array}$ & Any \\
\hline High-fidelity & $\bullet \bullet \bullet \circ \circ$ & $\bullet \bullet \bullet \bullet \circ$ & Optimisation of process params., & Medium \\
Hatch-by-hatch & $\bullet \bullet \bullet \circ \circ$ & $\bullet \bullet \bullet \circ \circ$ & scanning path design. & or large \\
\hline Layer-by-layer & $\bullet \bullet \circ \circ \circ$ & $\bullet \bullet \circ \circ \circ$ & Number of parts on single build, & Large \\
n-layer-by-n-layer & $\bullet \circ \circ \circ \circ$ & $\bullet \circ \circ \circ \circ$ & location and orientation of parts. & \\
\hline
\end{tabular}

TABLE 6. Comparison of simplified scanning strategies

- Excluding the powder-bed from the computational model reduces significantly the size of the spatial discretization and also the uncertainty associated to the approximation of the powder thermophysical properties. Nonetheless, it leads to a less physically representative model with lower accuracy. This modelling strategy should be avoided whenever the local thermal history must be accurately predicted.

- As for the scanning strategies, summarised in Table 6, the reduction of CPU-time is accompanied by poorer accuracy. In spite of this, high-fidelity and hatch-by-hatch techniques are already able to match the thermoucouple precision. For this reason, they are an efficient alternative to assist in many engineering decisions, such as selection of the process parameters, design of the scanning path, orientation of the part, or the number of parts printed in a build.

Apart from that, different domain sizes should be considered for different reduced models. In this sense, the authors recommend to use high-fidelity and hatch-by-hatch strategies from medium build sizes $\left(>100 \mathrm{~mm}^{3}\right)$, layer-by-layer strategies for large builds $\left(>10 \mathrm{~cm}^{3}\right.$ and $100-$ 500 layers), and multi-layered strategies only for very large builds with several components (> $100 \mathrm{~cm}^{3}$ and above 500 layers).

\section{Conclusions}

In this work, a FE framework for the numerical simulation of the heat transfer analysis of AM processes by powder-bed technology is detailed. The formulation is supplemented by an apropos FE activation technique to deal with the sintering process which transforms the metal powder into a new solid layer.

The numerical model accounts for the power input and the corresponding power absorption, the temperature dependency of the material properties and the heat dissipation through the boundaries by conduction, convection and radiation.

The experimental calibration of the model is performed by defining a benchmark manufactured using the EOSINT M280 machine available at MCAM laboratories and instrumented with different thermocouples. The scale of the experiment (geometry, number of layers, build time) is close to the current technological limits of the machine, but also a computational challenge, where specifying mesh sizes of the order of the laser spot size leads to extremely large problems.

In a first stage, the powder bed is excluded from the domain of analysis and the scanning sequence is approximated. Both assumptions have an impact on the accuracy of the local complex thermal history, but are necessary to carry out the calibration and sensitivity analysis in reasonable computational times. Even with these reductions, the model is capable of accurately capturing the global thermal response.

Heat dissipation through the powder bed is accounted for with an equivalent boundary condition in terms of Newton's law of cooling. This heat dissipation mechanism and the definition of the power input have been identified as the most sensitive mechanisms to assess the simulation accuracy.

In a next stage, different numerical strategies are analysed to find the best one in terms of computational cost vs simulation accuracy. First, the powder bed is added to the analysis. Afterwards, alternative scanning strategies are investigated by considering: simplified hatch-by-hatch patterns, layer-by-layer and multi-layer-by-multi-layer building sequences. 
Excluding the powder bed from the computational domain reduces CPU-time and avoids the characterisation of the material powder. However, it is necessary to define the equivalent HTC between the samples and the powder, as well as the average temperature of the powder far from the HAZ. The powder bed can be split into different regions with different average temperatures. This is relevant when more components are printed on the same building platform at the same time.

Regarding the scanning strategies, a layer-by-layer or a multi-layered approach significantly reduces the computational effort. However, this modelling strategy is only able to capture an average evolution of the temperature field during the manufacturing process. To capture the local thermal history at the thermocouples, the high-fidelity approach is preferred because the energy distribution according to the actual scanning sequence is retained. Finally, simplified hatch-by-hatch patterns strike a good balance between computational effort and accuracy, turning them into a competitive alternative for optimisation of process parameters and process planning.

\section{ACKNowledgements}

Financial support from the EC - Factories of the Future (FoF) Program under the $C A \times$ Man Project - Computer Aided Technologies for Additive Manufacturing - within Horizon 2020 Framework Programme is gratefully acknowledged.

E. Neiva gratefully acknowledges the support received from the Catalan Government through a FI fellowship. S. Badia gratefully acknowledges the support received from the Catalan Government through the ICREA Acadèmia Research Program. Financial support to CIMNE via the CERCA Programme / Generalitat de Catalunya.

The experimental work is funded by the Science \& Industry Endowment Fund program RP04153 Manufacturing a small demonstrator aero-engine entirely through additive manufacturing and Australia Research Council IH130100008 Industrial Transformation Research Hub for Transforming Australia's Manufacturing Industry through High Value Additive Manufacturing, including financial support from Safran Power Units and Amaero Engineering.

\section{REFERENCES}

[1] A. Anca, V. D. Fachinotti, G. Escobar-Palafox, and A. Cardona. Computational modelling of shaped metal deposition. International Journal for Numerical Methods in Engineering, 85(1): 84-106, Jan. 2011.

[2] G. Bugeda, M. Cervera, and G. Lombera. Numerical prediction of temperature and density distributions in selective laser sintering processes. Rapid Prototyping Journal, 5(1):21-26, 1999.

[3] M. Cervera, C. Agelet De Saracibar, and M. Chiumenti. Thermo-mechanical analysis of industrial solidification processes. International Journal for Numerical Methods in Engineering, 46(9):15751591, 1999.

[4] M. Cervera, C. Agelet de Saracibar, and M. Chiumenti. Comet: Coupled mechanical and thermal analysis. data input manual. Barcelona: International Center for Numerical Methods in Engineering (CIMNE), 2002.

[5] M. Chiumenti, C. A. de Saracibar, and M. Cervera. On the numerical modeling of the thermomechanical contact for metal casting analysis. Journal of Heat Transfer, 130(6):061301, 2008.

[6] M. Chiumenti, M. Cervera, A. Salmi, C. A. De Saracibar, N. Dialami, and K. Matsui. Finite element modeling of multi-pass welding and shaped metal deposition processes. Computer methods in applied mechanics and engineering, 199(37):2343-2359, 2010.

[7] M. Chiumenti, M. Cervera, N. Dialami, B. Wu, L. Jinwei, and C. Agelet de Saracibar. Numerical modeling of the electron beam welding and its experimental validation. Finite Elements in Analysis and Design, 121:118-133, 2016.

[8] M. Chiumenti, X. Lin, M. Cervera, W. Lei, Y. Zheng, and W. Huang. Numerical simulation and experimental calibration of additive manufacturing by blown powder technology. part i: thermal analysis. Rapid Prototyping Journal, 23(2):448-463, 2017. 
[9] K. Dai and L. Shaw. Distortion minimization of laser-processed components through control of laser scanning patterns. Rapid Prototyping Journal, 8(5):270-276, 2002.

[10] C. A. De Saracibar, M. Cervera, and M. Chiumenti. On the formulation of coupled thermoplastic problems with phase-change. International journal of plasticity, 15(1):1-34, 1999.

[11] D. Deng and H. Murakawa. Numerical simulation of temperature field and residual stress in multipass welds in stainless steel pipe and comparison with experimental measurements. Computational materials science, 37(3):269-277, 2006.

[12] D. Deng, H. Murakawa, and W. Liang. Numerical simulation of welding distortion in large structures. Computer methods in applied mechanics and engineering, 196(45):4613-4627, 2007.

[13] E. R. Denlinger, J. C. Heigel, and P. Michaleris. Residual stress and distortion modeling of electron beam direct manufacturing Ti-6al-4v. Proceedings of the Institution of Mechanical Engineers, Part B: Journal of Engineering Manufacture, 229(10):1803-1813, Oct. 2015.

[14] E. R. Denlinger, V. Jagdale, G. V. Srinivasan, T. El-Wardany, and P. Michaleris. Thermal modeling of Inconel 718 processed with powder bed fusion and experimental validation using in situ measurements. Additive Manufacturing, 11:7-15, July 2016. ISSN 2214-8604.

[15] E. R. Denlinger, M. Gouge, J. Irwin, and P. Michaleris. Thermomechanical model development and in situ experimental validation of the Laser Powder-Bed Fusion process. Additive Manufacturing, 16:73-80, Aug. 2017.

[16] A. J. Dunbar, E. R. Denlinger, M. F. Gouge, and P. Michaleris. Experimental validation of finite element modeling for laser powder bed fusion deformation. Additive Manufacturing, 12, Part A: 108-120, Oct. 2016.

[17] J. Goldak, A. Chakravarti, and M. Bibby. A new finite element model for welding heat sources. Metallurgical transactions B, 15(2):299-305, 1984.

[18] J. A. Goldak and M. Akhlaghi. Computational welding mechanics. Springer Science \& Business Media, 2006.

[19] N. E. Hodge, R. M. Ferencz, and R. M. Vignes. Experimental comparison of residual stresses for a thermomechanical model for the simulation of selective laser melting. Additive Manufacturing, 12, Part B:159-168, Oct. 2016.

[20] D. Hu and R. Kovacevic. Modelling and measuring the thermal behaviour of the molten pool in closed-loop controlled laser-based additive manufacturing. Proceedings of the Institution of Mechanical Engineers, Part B: Journal of Engineering Manufacture, 217(4):441-452, 2003.

[21] J. Irwin and P. Michaleris. A Line Heat Input Model for Additive Manufacturing. Journal of Manufacturing Science and Engineering, 138(11):111004-111004-9, June 2016.

[22] S. Kolossov, E. Boillat, R. Glardon, P. Fischer, and M. Locher. 3d FE simulation for temperature evolution in the selective laser sintering process. International Journal of Machine Tools and Manufacture, 44(2-3):117-123, Feb. 2004.

[23] M. Labudovic, D. Hu, and R. Kovacevic. A three dimensional model for direct laser metal powder deposition and rapid prototyping. Journal of materials science, 38(1):35-49, 2003.

[24] P. Lacki and K. Adamus. Numerical simulation of the electron beam welding process. Computers ES Structures, 89(11):977-985, 2011.

[25] Y. Lee and W. Zhang. Modeling of heat transfer, fluid flow and solidification microstructure of nickel-base superalloy fabricated by laser powder bed fusion. Additive Manufacturing, 12:178-188, oct 2016.

[26] Y. Li and D. Gu. Thermal behavior during selective laser melting of commercially pure titanium powder: Numerical simulation and experimental study. Additive Manufacturing, 1-4:99-109, oct 2014.

[27] L.-E. Lindgren. Computational welding mechanics. Elsevier, 2014.

[28] A. Lundbäck and L.-E. Lindgren. Modelling of metal deposition. Finite Elements in Analysis and Design, 47(10):1169-1177, Oct. 2011.

[29] S. Marimuthu, D. Clark, J. Allen, A. Kamara, P. Mativenga, L. Li, and R. Scudamore. Finite element modelling of substrate thermal distortion in direct laser additive manufacture of an aeroengine component. Proceedings of the Institution of Mechanical Engineers, Part C: Journal of 
Mechanical Engineering Science, 227(9):1987-1999, 2013.

[30] L. Parry, I. Ashcroft, and R. Wildman. Understanding the effect of laser scan strategy on residual stress in selective laser melting through thermo-mechanical simulation. Additive Manufacturing, 12:1-15, Oct. 2016.

[31] N. Patil, D. Pal, H. Khalid Rafi, K. Zeng, A. Moreland, A. Hicks, D. Beeler, and B. Stucker. A Generalized Feed Forward Dynamic Adaptive Mesh Refinement and Derefinement Finite Element Framework for Metal Laser Sintering-Part I: Formulation and Algorithm Development. Journal of Manufacturing Science and Engineering, 137(4):041001, Aug. 2015.

[32] R. B. Patil and V. Yadava. Finite element analysis of temperature distribution in single metallic powder layer during metal laser sintering. International Journal of Machine Tools and Manufacture, 47(7):1069-1080, 2007.

[33] P. Peyre, P. Aubry, R. Fabbro, R. Neveu, and A. Longuet. Analytical and numerical modelling of the direct metal deposition laser process. Journal of Physics D: Applied Physics, 41(2):025403, 2008.

[34] P. Prabhakar, W. Sames, R. Dehoff, and S. Babu. Computational modeling of residual stress formation during the electron beam melting process for Inconel 718. Additive Manufacturing, 7: 83-91, July 2015.

[35] M. Rahman, W. Maurer, W. Ernst, R. Rauch, and N. Enzinger. Calculation of hardness distribution in the haz of micro-alloyed steel. Welding in the World, 58(6):763-770, 2014.

[36] I. A. Roberts, C. J. Wang, R. Esterlein, M. Stanford, and D. J. Mynors. A three-dimensional finite element analysis of the temperature field during laser melting of metal powders in additive layer manufacturing. International Journal of Machine Tools and Manufacture, 49(12-13):916-923, Oct. 2009.

[37] D. Rosenthal. Mathematical theory of heat distribution during welding and cutting. Welding journal, 20(5):220s-234s, 1941.

[38] B. Song, S. Dong, H. Liao, and C. Coddet. Process parameter selection for selective laser melting of Ti6al4v based on temperature distribution simulation and experimental sintering. The International Journal of Advanced Manufacturing Technology, 61(9-12):967-974, Aug. 2012.

[39] The Common Layer Interface (CLI) universal format. Common Layer Interface (CLI) Version 2.0 File Description, (n.d.). Accessed: 2016-08-26.

[40] Y. Tian, C. Wang, D. Zhu, and Y. Zhou. Finite element modeling of electron beam welding of a large complex al alloy structure by parallel computations. journal of materials processing technology, 199(1):41-48, 2008.

[41] B. Xiao and Y. Zhang. Laser sintering of metal powders on top of sintered layers under multipleline laser scanning. Journal of Physics D: Applied Physics, 40(21):6725, 2007.

[42] S. Xue and J. W. Barlow. Models for the Prediction of the Thermal Conductivities of Powders. In Solid Freeform Fabrication Symposium Proceedings, pages 62-69. Center for Materials Science, University of Texas at Austin Austin, Tex., 1991.

[43] S. Yagi and D. Kunii. Studies on effective thermal conductivities in packed beds. AIChE Journal, 3(3):373-381, Sept. 1957.

[44] J. Yin, H. Zhu, L. Ke, W. Lei, C. Dai, and D. Zuo. Simulation of temperature distribution in single metallic powder layer for laser micro-sintering. Computational Materials Science, 53(1): 333-339, 2012.

[45] S. Zekovic, R. Dwivedi, and R. Kovacevic. Thermo-structural finite element analysis of direct laser metal deposited thin-walled structures. In Proceedings SFF Symposium,. Austin, TX, 2005.

[46] D. Q. Zhang, Q. Z. Cai, J. H. Liu, L. Zhang, and R. D. Li. Select laser melting of W-Ni-Fe powders: simulation and experimental study. The International Journal of Advanced Manufacturing Technology, 51(5-8):649-658, Nov. 2010.

[47] L. Zhang, E. W. Reutzel, and P. Michaleris. Finite element modeling discretization requirements for the laser forming process. International Journal of Mechanical Sciences, 46(4):623-637, Apr. 2004. 